\title{
Macromammalian faunas, biochronology and palaeoecology of the early Pleistocene Main Quarry hominin-bearing deposits of the Drimolen Palaeocave System, South Africa
}

Justin W Adams, Douglass S Rovinsky, Andy IR Herries, Colin G Menter

The Drimolen Palaeocave System Main Quarry deposits (DMQ) are some of the most prolific hominin and primate-bearing deposits in the Fossil Hominids of South Africa UNESCO World Heritage Site. Discovered in the 1990s, excavations into the DMQ have yielded a demographically diverse sample of Paranthropus robustus (including DNH 7, the most complete cranium of the species recovered to date), early Homo, Papio hamadryas robinsoni and Cercopithecoides williamsi. Alongside the hominin and primate sample is a diverse macromammalian assemblage, but prior publications have only provided a provisional species list and an analysis of the carnivores recovered prior to 2008. Here we present the first description and analysis of the non-primate macromammalian faunas from the DMQ, including all 826 taxonomically identifiable specimens catalogued from over two decades of excavation. We also provide a biochronological interpretation of the DMQ deposits and an initial discussion of local palaeoecology based on taxon representation. The current DMQ assemblage consists of the remains of minimally 147 individuals from 9 Orders and 14 Families of mammals. The carnivore assemblage described here is even more diverse than established in prior publications, including the identification of Megantereon whitei, Lycyaenops silberbergi, and first evidence for the occurrence of Dinofelis cf. barlowi and Dinofelis aff. piveteaui within a single South African site deposit. The cetartiodactyl assemblage is dominated by bovids, with the specimen composition unique in the high recovery of horn cores and dominance of Antidorcas recki remains. Other cetartiodactyl and perissodactyl taxa are represented by few specimens, as are Hystrix and Procavia; the latter somewhat surprisingly so given their common occurrence at penecontemporaneous deposits in the region. Equally unusual (particularly given the size of the sample) is the identification of single specimens of giraffoid, elephantid and aardvark (Orycteropus cf. afer) that are rarely recovered from regional site deposits.Despite the diversity within the DMQ macromammalian faunas there are few habitat- or biochronologically-sensitive species that provide specific ecologic or age boundaries for the deposits. Recovered species can only support the non-specific, mixed open-to-closed palaeohabitats around Drimolen that have been reconstructed for the other 
penecontemporaneous South African palaeokarst deposits. The identified Equus quagga ssp. specimens recovered from the floor of the current excavation ( -4.5-5 m below datum) suggests that most, if not all the DMQ specimens, were deposited after $2.33 \mathrm{Ma}$. Simultaneously, the carnivore specimens (D. cf. barlowi, L. silberbergi) suggest earlier Pleistocene (pre- 2.0-1.8 Ma) to maximally 1.6 Ma deposition ( $D$. aff. piveteaui) for most of the DMQ fossil assemblage. 
1 Macromammalian faunas, biochronology and palaeoecology of the early Pleistocene Main 2 Quarry hominin-bearing deposits of the Drimolen Palaeocave System, South Africa

3

4 Justin W. Adams ${ }^{1 \# *}$, Douglass S. Rovinsky ${ }^{1 \#}$, Andy I.R. Herries ${ }^{2,3}$, Colin G. Menter ${ }^{3}$

\section{5}

6

7

8

$9{ }^{1}$ Department of Anatomy and Developmental Biology, Monash University, Melbourne, Victoria

10 3800, justin.adams@monash.edu; rovinsky.d@gmail.com, +61 0399024280

11

$12{ }^{2}$ The Australian Archaeomagnetism Laboratory, Dept. Archaeology and History, La Trobe

13 University, Melbourne Campus, Bundoora, Victoria 3086, Australia; a.herries@latrobe.edu.au, $14+610394791392$

15

$16{ }^{3}$ Centre for Anthropological Research, University of Johannesburg, Auckland Park 2006, South

17 Africa, menterc@drimolen.org, +27 0115591919

18

19

20

21

\#Shared first authorship based on equal contributions to the research and manuscript

22

$23 *$ *orresponding author: justin.adams@monash.edu 


\section{Abstract}

28 The Drimolen Palaeocave System Main Quarry deposits (DMQ) are some of the most prolific

29 hominin and primate-bearing deposits in the Fossil Hominids of South Africa UNESCO World 30 Heritage Site. Discovered in the 1990s, excavations into the DMQ have yielded a 31 demographically diverse sample of Paranthropus robustus (including DNH 7, the most complete 32 cranium of the species recovered to date), early Homo, Papio hamadryas robinsoni and 33 Cercopithecoides williamsi. Alongside the hominin and primate sample is a diverse 34 macromammalian assemblage, but prior publications have only provided a provisional species 35 list and an analysis of the carnivores recovered prior to 2008 . Here we present the first 36 description and analysis of the non-primate macromammalian faunas from the DMQ, including 37 all 826 taxonomically identifiable specimens catalogued from over two decades of excavation. 38 We also provide a biochronological interpretation of the DMQ deposits and an initial discussion 39 of local palaeoecology based on taxon representation.

41 The current DMQ assemblage consists of the remains of minimally 147 individuals from 9

42 Orders and 14 Families of mammals. The carnivore assemblage described here is even more 43 diverse than established in prior publications, including the identification of Megantereon whitei, 44 Lycyaenops silberbergi, and first evidence for the occurrence of Dinofelis cf. barlowi and 45 Dinofelis aff. piveteaui within a single South African site deposit. The cetartiodactyl assemblage 46 is dominated by bovids, with the specimen composition unique in the high recovery of horn 
47 cores and dominance of Antidorcas recki remains. Other cetartiodactyl and perissodactyl taxa are

48 represented by few specimens, as are Hystrix and Procavia; the latter somewhat surprisingly so

49 given their common occurrence at penecontemporaneous deposits in the region. Equally unusual

50 (particularly given the size of the sample) is the identification of single specimens of giraffoid,

51 elephantid and aardvark (Orycteropus cf. afer) that are rarely recovered from regional site 52 deposits.

53

54 Despite the diversity within the DMQ macromammalian faunas there are few habitat- or 55 biochronologically-sensitive species that provide specific ecologic or age boundaries for the 56 deposits. Recovered species can only support the non-specific, mixed open-to-closed 57 palaeohabitats around Drimolen that have been reconstructed for the other penecontemporaneous 58 South African palaeokarst deposits. The identified Equus quagga ssp. specimens recovered from 59 the floor of the current excavation ( - 4.5-5 m below datum) suggests that most, if not all the 60 DMQ specimens, were deposited after 2.33 Ma. Simultaneously, the carnivore specimens 61 (D. cf. barlowi, L. silberbergi) suggest earlier Pleistocene (pre- 2.0-1.8 Ma) to maximally 1.6 Ma 62 deposition (D. aff. piveteaui) for most of the DMQ fossil assemblage. 
Introduction

77 The Drimolen fossil site was discovered in 1992 during survey of the region for a sinkhole by Dr

78 A.W. Keyser (then with the Geological Survey of South Africa; since 1993 known as the

79 Council for Geoscience, one of the National Science Councils of South Africa) (Figures 1 and 2).

80 During his third site visit a hominin tooth was found from one of the 'Main Pinnacles', which led

81 to ad-hoc calcified sediment collection and mechanical preparation of fossil specimens from

821992 to mid-1994. In October 1994, a five-by-five metre alphanumeric grid was erected in the

83 Main Quarry along with three fixed theodolite stations; shortly thereafter excavations into the

84 decalcified material began that led to the recovery of the DNH 7 and 8 Paranthropus robustus

85 specimens from the 'Eurydice Pinnacle' (Keyser et al., 2000). From 1995 until 2009, the site was

86 excavated for 10 months out of the year, during which time changes to the grid system (e.g.,

87 numeric) and calcified sediment extraction methods (e.g., feather-and-wedge vs. drilling) were

88 introduced. Although greatly reduced excavation seasons ( $\sim 6$ weeks per year) have been

89 employed from 2010 to the present, this nearly 25-year history of sampling the Main Quarry

90 deposits has led to the recovery of a substantial assemblage of Paranthropus robustus and Homo

91 sp. remains, as well as non-hominin primate and other faunal remains (Keyser et al., 2000; 
92 Gommery, Senut \& Keyser, 2002; Lockwood et al., 2007; O’Regan and Menter, 2009; Moggi-

93 Cecchi et al., 2010; Gallagher and Menter, 2011)

94

95 These excavations into the Main Quarry, and progressive exposure of the Drimolen Palaeocave

96 System, has established that the site consists of a single large cavern in-filled with three main

97 types of sedimentary deposits (speleothem, breccia, siltstone/sandstone) that often grade from

98 one to the other laterally across the exposures (Figure 2; Keyser et al., 2000). The base of the

99 sequence consisted of a thick flowstone speleothem deposit that was extensively mined at the

100 turn of the $20^{\text {th }}$ century. This formed an undulating basal floor onto which all the other deposits

101 and fossil were deposited. This basal speleothem consists of clast-poor layers of flowstone with a

102 sharp contact to the overlying fossil-bearing sediments. As such, it formed a significant time

103 before an entrance formed allowing the clastic deposits to enter the cave.

105 In the centre of the Main Quarry a thick clast-supported, fossil-bearing breccia (referred to by

106 Keyser et al. [2000] as the 'Blocky Breccia') occurred that represents the opening and

107 subsequent collapse of a vertical entrance to the cave forming a central debris cone. This is best

108 preserved against the western wall of the cavern where the deposits remain indurated (Figure 2).

109 The eastern part of this debris cone has suffered from collapse due to undercutting by lime

110 miners removing the basal speleothem; as a result, the very eastern part of the Main Quarry was

111 filled with mining debris and removal has accelerated the decalcification of these deposits.

112

113 During phases of flooding, the fine-grained fraction within the blocky breccia was then

114 winnowed to the edges of the cavern to form a series of interstratified siltstone and sandstone 
115 deposits (referred to by Keyser et al. [2000] as 'Cave Siltstone'). As a result, these two

116 sedimentological deposits are contemporary and the clast-supported breccia of the central debris

117 cone grades through a matrix-supported breccia and into the laminated siltstone and sandstone

118 deposits towards the edge of the cavern. This exact sequence of formation can be seen at the

119 nearby Wonder Cave active karstic system. The oldest siltstone and sandstone deposits in-filled

120 the southern area of the Main Quarry. As the debris cone began to grow upwards and expand

121 laterally it became less steep and matrix supported breccia became more prevalent. It is possible

122 that at this time the original vertical shaft entrance, that would have initially restricted the access

123 of certain animals to the cave, may have become so in-filled with sediments that entry became

124 more accessible via a shallow talus cone into the fine-clastic sediment floors at the edge of the

125 cavern. The southern area of the Main Quarry had become completely in-filled during this early

126 phase due to the presence of a stepped cave roof, leading to concentrated deposition of the fine-

127 grained siltstone and sandstone in the northern area of the cavern. It is notable that macrofaunal

128 remains have not been recovered from the oldest southern siltstone and sandstone deposits, but

129 are instead recovered either from the northern siltstone and sandstone deposits or from the

130 central talus cone, suggesting that they could have been washed into the cave or that animals

131 inhabiting the cavern stayed in the daylight zone around the entrance. Despite this there is little

132 to suggest that the two periods are separated by any significant time interval, other than a series

133 of thin $(<2 \mathrm{~cm})$ flowstones forming during the deposition of the northern siltstone and sandstone

134 deposits.

135

136 Despite the decades of excavation into the Drimolen Palaeocave System, to date only a basic

137 listing of macromammlian taxa recovered from the first years of Main Quarry deposits (Keyser 
138 et al., 2000) and a more comprehensive analysis of the Order Carnivora (O'Regan and Menter,

139 2009) have been previously published. This analysis provides the first primary description of the

140 entire macromammalian (e.g., all Orders other than Macroscelidea, Insectivora, and Rodentia

141 [exc. Family Hystricidae]) faunal assemblage excavated from the Drimolen Main Quarry since

142 palaeontological sampling began in the early 1990s. We only present data on the fossil

143 specimens attributable to at least Order as the taxonomically non-diagnostic remains from the

144 deposits form the basis for a separate study reconstructing the taphonomy of the Main Quarry 145 deposits.

\section{Materials and Methods}

149 The Drimolen Main Quarry (DMQ) fossil assemblage is curated in the Evolutionary Studies

150 Institute at the University of the Witwatersrand and consists of 1380 specimens derived from

151 excavation of decalcified sediments and processed calcified sediment blocks (Keyser et al.,

152 2000). Since the start of the excavations, the Drimolen Main Quarry decalcified material has

153 been excavated in one-by-one meter (or smaller) squares in $10 \mathrm{~cm}$ increments and all material

154 has been sieved through three different mesh sizes (the smallest being $\sim 1 \mathrm{~mm}$ ). The sieving

155 regimen, though, has undergone some changes over the years with wet sieving of the smallest

156 mesh size from 1997 along with all these "fines" being sorted at a sorting table and not just

157 quickly "over the sieve". Since 2014, we have also wet sieved the medium fraction via a water 158 pump and all the "fines" are now sorted in the lab over the following year. Prior to 2003, the

159 only provenience for the decalcified material was by its grid square and $10 \mathrm{~cm}$ level boundaries.

160 Since 2003, a total station theodolite has been permanently used at Drimolen allowing 
161 identifiable specimens or fragments larger than $2 \mathrm{~cm}$ to be directly piece-plotted in reference to a

162 three-dimensional model of the deposits created via a Trimble laser scanner in 2012 (via the

163 University of Cape Town Zamani Project) and again in 2015 with a Leica Nova MS50

164 multistation (from La Trobe University).

165

166 All calcified breccia blocks have been removed from the Main Pinnacles through standard

167 feather-and-wedge techniques. Most of the calcified material was removed in the 1990s with no

168 drilling of breccia after this period. Prior to 1997, this calcified material was either surveyed with

169 a theodolite (without electronic distance meter) or at the very least the Pinnacle number or plane

170 table location was recorded on the block. Since 1997, all calcified blocks were only sampled

171 when a total station was available and were surveyed with at least six survey points. Breccia

172 blocks within a decalcified excavation square were also recorded in this manner. The only other

173 sampling of calcified material has been removing blocks that are decalcifying from the 'Eurydice

174 Pinnacle'. This material is prepared mechanically until close to the bone and then the reduced

175 block is prepared via acetic acid processing.

176

177 For this analysis we only considered specimens preserving sufficient morphology to be identified

178 at least to Order level and are not presenting data on indeterminate mammalian elements or

179 fragments. We have also not undertaken an analysis of the 554 primate craniodental and

180 postcranial specimens, as this collection has recently been partially analysed (see Nieuwoudt,

181 2014). We have also not duplicated the primary description of the Main Quarry carnivores of

182 O'Regan and Menter (2009), but we have re-evaluated the previously published Dinofelis and 
183 Chasmaporthetes specimens because of their bearing on biochronological interpretations and

184 present data on carnivore specimens catalogued since publication of that study.

185

186 The taxonomic and/or element attributions were made in direct reference to the extant mammal

187 skeletal materials of the Department of Vertebrates (Large Mammal, Small Mammal and

188 Archaeozoology Sections) collections of the Ditsong National Museum of Natural History

189 (Pretoria, South Africa), previously described fossil specimens in the Plio-Pleistocene Section of

190 the Ditsong Museum and Evolutionary Studies Institute of the University of the Witwatersrand

191 (Johannesburg, South Africa). All measurements of specimens reported here were taken using

192 Mitutoyo $150 \mathrm{~mm}$ calipers with a direct digital input, including dental (MD: mesiodistal, BL:

193 buccolingual; taken at the level of occlusion unless otherwise noted) and horn core metrics (AP:

194 anteroposterior, ML: mediolateral; taken at the level of the pedicle unless otherwise noted).

195 Three-dimensional (3D) surface scans were captured with an Artec Spider (Artec Group,

196 Luxembourg) to facilitate morphological comparisons of some of the specimens following

197 methods described in Adams et al. (2015). In some cases, external specimens were examined

198 using a Dino-Lite Edge AM4815ZTZ microscope (AnMo Electronics Corp.).

200 In order to facilitate discussion and integrate the DMQ assemblage within the broader South

201 African late Pliocene and Pleistocene fossil record, we draw from the extensive published

202 literature on the well-described penecontemporaneous South African fossil deposit faunal 203 assemblages (e.g., Bolt's Farm, Gondolin, Haasgat, Kromdraai, Swartkrans, Sterkfontein). To

204 facilitate comparisons of the proportion (based on the minimum number of individuals, MNI) of

205 mammals in the DMQ deposits relative to other South African assemblages we have also 
206 calculated the McIntosh evenness statistic (McIntosh, 1967). We would note, however, that such

207 direct comparisons of faunal assemblages assume that the taphonomic histories of these deposits

208 (from predepositional processes and time-averaging to excavation/sampling methodologies) have

209 not introduced substantial biases in the faunal representation or abundance; an assumption that

210 may not always be warranted as each deposit has an idiosyncratic depositional history (see

211 discussions in Brain, 1981; Reed, 1996; Pickering, 1999; Adams, 2006). As a comprehensive

212 taphonomic analysis of the DMQ assemblage is still ongoing, we will not address the role

213 taphonomic processes had in shaping the faunal presence/absence/abundance with the Main

214 Quarry deposits at this time. We also largely do not consider the more recently described faunal

215 assemblages (e.g., Motsetse [Berger and Lacruz, 2003], Hoogland [Adams et al., 2010], Malapa

216 [Dirks et al., 2010; Kuhn et al., 2012]) as the faunal data from these localities is based on

217 extremely small sample sizes and generally limited to simple listings without primary

218 descriptions or supporting data.

219

220 Results

221

222 The current listing of identified non-hominin specimens (number of individual specimens, NISP;

223 MNI) from the Drimolen Main Quarry is provided in Table 1, including primate specimens

224 described in Nieuwoudt (2014) and carnivore specimens described in O'Regan and Menter 225 (2009).

226

227 Systematic Palaeontology

228 
Referred specimens. DN 2791, right partial maxillary canine.

241 Description. This single partial canine is the first specimen from the site to be considered comparable to Dinofelis barlowi (Figure 3A). The canine exhibits greater transverse crown compression than present in pantherines like extant and contemporaneous Panthera pardus Linnaeus, 1758 canines from Swartkrans Member 1 (e.g., SK 349 [0.77], SK 354 [0.75]) (Table 3; Figure 4). The size and transverse crown compression of DN 2791 is consistent with the machairodonts Dinofelis piveteaui Ewer, 1955a KA 61 type specimen (0.59; BL: $12.1 \mathrm{~mm}$ / MD:

$24720.5 \mathrm{~mm}$ ) and Dinofelis barlowi BF-55 22 specimen (0.59; BL: $14.5 \mathrm{~mm} / \mathrm{MD}: 24.5 \mathrm{~mm})$. In 248 contrast to the canines of the KA 61 D. piveteaui specimen, the DN 2791 specimen is both more 249 curved from root to crown, more oval in cross-section, and lacks the well-developed distal 250 carina. The DN 2791 specimen is, however, identical to BF-55 22 in root-to-crown curvature, the 251 ovoid cross-sectional shape, and the development of the mesial and distal carinae. Based on these 
252 comparisons we provisionally attribute the canine to $D$. cf. barlowi. We discuss the significance

253 of this novel specimen relative to the previously published DMQ Dinofelis aff. piveteaui

254 craniodental and postcranial specimens (O’Regan and Menter, 2009) below.

255

256

257

258

259

260

261

262

263

264

265

266

267

268

269

270

271

272

273

274
Genus MEGANTEREON Croizet and Jobert 1828

Type species Megantereon cultridens Cuvier, 1824

Megantereon whitei Broom, 1937

Referred specimens. DN 976, left partial P4; DN 3254, left mandibular symphysis and corpus with partial canine.

Description. Two specimens represent the machairodont Megantereon whitei from the Drimolen Main Quarry deposits. The DN 976 left P4, while broken and reglued with slight distortion on the lingual aspect, preserves part of the protocone, paracone and metastyle (Figure 3B; Table 2). The protocone is extremely small and grades smoothly into the upright paracone. There is a deep notch separating the paracone and bulbous metacone, and a distinct notch on the metastyle. This morphology is shared with the KA 64 Megantereon whitei P4 to the exclusion of other machairodonts (e.g., Dinofelis piveteaui, Dinofelis barlowi), similarly-sized extant felids (e.g., Panthera pardus, Acinonyx jubatus Schreber, 1775), or the indeterminate Main Quarry felids (DN 530, 4300, 5498) described below. 
275 The DN 3254 left partial mandible preserves part of the symphysis and alveolus for the i1-i3, the

276 canine alveolus with part of the canine root, and the diastema (Figure 3C). Although this

277 specimen preserves the anterior portion that does not overlap other South African M. whitei

278 mandibles (e.g., KA 64, TM 856, STS 1588; Ewer, 1955a; Turner, 1987a), several

279 morphological features align the specimen with $M$. whitei; the most diagnostic of these features

280 is the presence of a mandibular flange on the anterolateral border of the corpus adjacent to the

281 canine alveolus. The root of the canine indicates the tooth was small (length: $12.5 \mathrm{~mm}$, breadth:

$2827.1 \mathrm{~mm}$ ) and consistent with other African and Eurasian Megantereon specimens (Palmqvist et

283 al., 2007). Finally, the diastema is sharply margined and elongated given the absence of any

284 premolar alveolus despite the preserved length of the corpus.

285

286

287

288

289

290

291

292

293

294 Description. A small collection of carnivore craniodental and postcranial specimens are 295

Felidae gen. et sp. indet.

Referred specimens. DN 530, right P4; DN 558, left proximal ulna; DN 2236, terminal phalanx; DN 2701, left partial mandible; DN 2937, indet. maxillary incisor; DN 3291, right calcaneus; DN 4300, right P4 (probable antimere to DN 5498); DN 4354, two associated indet. mandibular incisors; DN 4590, right partial astragalus; DN 5498, left P4 (probable antimere to DN 4300).

attributable to the Family Felidae but are not considered sufficiently diagnostic to attribute to genus or species. The DN 558 left proximal ulna preserves part of the olecranon process and articular surface and is derived from a large, Dinofelis-sized felid but is too damaged to 
298 confidently attribute. Also likely derived from a larger felid is the DN 3291 partial calcaneus and

299 DN 4590 partial astragalus, with the latter similar to the previously described DN 2149b $D$. aff.

300 piveteaui astragalus (O'Regan and Menter, 2009: 338). In contrast the DN 2236 phalanx is from

301 a smaller felid species that appears slightly larger than extant caracal (Caracal caracal Schreber,

302 1776) and preserves a robust volar surface. The DN 2937 maxillary incisor is tall, pointed, and

303 distinctly tricusped, preserving parts of two discrete lingual accessory cusps and is consistent

304 with derived machairodont incisors (e.g., BF-55 23 D. barlowi, KA 61 D. piveteaui, KA 64

305 Megantereon whitei; Biknevicius, Van Valkenburgh \& Walker, 1996; Christiansen and

306 Adolfssen, 2007); the similarly-shaped DN 4354 mandibular incisors are also likely derived from

307 a machairodont felid, perhaps the same individual, given their shared size and distinct

308 morphology.

309

310 Four of the indeterminate felid craniodental specimens may ultimately be attributable below the

311 level of Family with additional analysis beyond this primary description. The DN 2701 left

312 mandible preserves the posterior portions of the corpus, including gonion and the condylar and

313 coronoid processes. The masseteric fossa is deep and exhibits robust scarring both dorsal and

314 ventral to the margins. The specimen is much smaller than D. barlowi (BF-55 23) and $D$.

315 piveteaui (KA 62, KA 63) mandibular remains, but similar in size to both $M$. whitei (KA 64, STS

316 1588) and P. pardus (extant comparative and SK 349) mandibles. However, in contrast with

317 extant $P$. pardus mandibles (and SK 349) the DN 2701 coronoid process is shorter, narrower

318 anteroposteriorly, and less robust. In addition, the DN 2701 gonion exhibits less lateral flare and

319 the condyle is more robust and angled relative to the axis of the corpus. The DN 2701 coronoid

320 process is also smaller and less robust than that of the KB 5224b M. whitei mandible from 
321 Kromdraai B (Turner, 1987a), but shows a similar condylar morphology to both the KB 5224b

322 and KA 64 specimens. Unfortunately, this region is poorly preserved or absent in other South

323 African Megantereon mandibles to assess potential variability in coronoid process morphology

324 that may eventually provide for a more confident attribution of the DN 2701 specimen.

325

326 The DN 530, 4300 and DN 5498 maxillary fourth premolars all preserve similar cusp

327 morphologies (DN 4300 and DN 5498 are probable antimeres based on shared morphology and

328 spatial position in the deposits) and are likely derived from the same felid species (Figure 5A).

329 The DN 530 specimen exhibits damage to the crown elements, and the DN 5498 P4 was broken

330 in three places and reglued; however, the latter retains some of the maxillary alveolar bone

331 including the alveolus for the M1, which indicates a robust, ovoid and possibly double-rooted

332 M1 in life. All of these specimens exhibit weakly-developed protocones that grade smoothly into

333 the paracone, and a deep cleft dividing the paracone and metastyle. They are all larger than

334 extant Acinonyx jubatus and Panthera pardus (comparative measurements in Turner, 1984;

335 Table 2) and also differ in protocone size (e.g., more developed than in A. jubatus, less separated

336 from the paracone and more distally positioned than in P.pardus). None of these specimens can

337 be accommodated into Dinofelis based on their size and morphology of the parastyle and

338 metastyle (Table 2). The closest metric and morphological match for these Main Quarry

339 specimens is the KA 64 Megantereon whitei P4; however, the DN specimens exhibit a parastyle

340 more distinct from the paracone, a more rudimentary ectostyle, no buccolingual pinching of the

341 metastyle, and a flared posterior lip of the metacone (Figure 5A). Lacking a strong

342 morphological match for these specimens, we have deferred a more specific taxonomic

343 attribution of the specimens pending further analysis. 
353 Referred specimens. DN 974, right P3.

355 Description. A primary description of the DN 974 specimen was provided in O'Regan and

356 Menter (2009), although we differ in treating the DN 974 specimen as a right P3 rather than a 357 right $\mathrm{P} 2$ based on size and morphology (Figure 5B; Table 3). In the original description, 358 O'Regan and Menter (2009: 343-344) allocated DN 974, and the DN 404 partial cranium, to 359 Chasmaporthetes nitidula Hay, 1921 based on dental metrics and interpretation of mesial 360 accessory cusp and P4 morphology relative to the Swartkrans Member 1 C. nitidula specimens 361 (specifically SK 305, 306, and 307) and previously published descriptions by Broom (1948) and 362 Ewer (1955b).

364 In contrast to the prior taxonomic attribution, the preserved morphology of the DN 974 specimen 365 is most consistent with the type specimen and other African specimens of Lycyaenops 366 silberbergi. The DN 974 right third premolar preserves a tall paracone and a large distal 
367 accessory cusp, but no mesial accessory cusp and only a modest mesial cingulum. The crown is 368 rectangular in outline, has a distally-shifted lingual shelf well-separated from the paracone, and

369 the paracone is separated from the distal accessory cusp by a distinct 'waist', particularly well370 developed on the labial aspect. This morphology is shared with the L. silberbergi P3 type (STS 371 130) and other specimens from Sterkfontein Member 4 (STS 127, 130, 135; SF 369/372, 372 383/373, 408) and the Lycyaenops $\mathrm{cf}$. L. silberbergi from Laetoli (NHM AS 7.VI.35, LAET 75373 494) (Turner, 1986, 1990; Werdelin and Dehghani, 2011). It differs from the C. nitidula P3s 374 from Swartkrans Member 1 (SK 305, 306, 309, 312, 313) and Member 3 (SKX 29205) in the 375 development of the strong waist on the labial aspect and generally in mesial accessory cusp 376 morphology (Ewer, 1955b; Brain, 1981; Turner, 1993). We echo prior publications that there is 377 some variability in mesial accessory cusp expression across C. nitidula maxillary premolars (e.g., 378 Brain, 1981: 234 'type A, primitive' and 'type B, advanced'; Werdelin and Peigné, 2010);

379 however, only SK 305 and 306 preserve a more reduced mesial accessory cusp (the former is 380 damaged in this region) and both have more developed mesial cusps than that seen on DN 974.

381 As noted by O'Regan and Menter (2009) the DN 404 dentition is damaged, but the P3 has a 382 distinctly oval profile and smooth labial contour; the mesial and lingual aspects of the crown are 383 somewhat crushed and offset, prohibiting confident morphological assessment but likely 384 exhibited a modest mesial accessory cusp (and is closely resembling the 'type A, primitive' 385 Swartkrans Member 1 SK 306 partial maxilla). 
390 Referred specimens. DN 2864, partial right scapula; DN 2973, partial right P4; DN 3281,

391 partial right $\mathrm{P} 2$.

392

393 Description. In addition to the four indeterminate hyaenid craniodental and postcranial

394 specimens described by O'Regan and Menter (2009), three further elements can be attributed to

395 the family. The DN 2864 scapula preserves a very large infraglenoid tubercle relative to the size

396 of the preserved glenoid fossa and is derived from hyaenid smaller than extant Parahyaena

397 brunnea Thunberg, 1820. The DN 2973 right P4 preserves the complete protocone and lingual

398 aspect of the anterior accessory cusp and paracone with little occlusal wear. There is some

399 buccolingual swelling on the paracone that is shared with extant $P$. brunnea P4s and the SK 327

400 P. brunnea P4 from Swartkrans Member 1 (although smaller than the latter), and there is no

401 evidence for buccolingual compression or a ridge leading to the trigon basin as in Crocuta

402 crocuta. This specimen, along with the DN $2321 \mathrm{P} 4$ fragment described by O'Regan and Menter

403 (2009: 344), support the occurrence of a hyaenid individual distinct from Lycyaenops and

404 Chasmaporthetes in the Main Quarry deposits. In contrast, the DN 3281 right P2 preserves the

405 anterior margin of the crown and half of the anterior root that lacks the cingulum distinctive for

406 P. brunnea dentition. The specimen preserves strong labial ridging and a flattened lingual aspect,

407 and is too buccolingually expanded to represent Chasmaporthetes or Lycyaenops. The closest

408 extant morphological match is Crocuta crocuta; minimally suggesting an additional hyaenid

409 distinct from L. silberbergi, C. nitidula, and the DN 2973/2321 individuals.

410

411

412

Order CETARTIODACTYLA Montgelard et al., 1997 
422 Referred specimens. DN 704, left maxillary third molar; DN 1111a, right maxillary second 423 molar.

425 Description. Only two of the identifiable alcelaphin specimens represent the genus 426 Connochaetes in the Main Quarry sample. The DN 704 third molar, derived from decalcified 427 sediments, is a complete crown (ML: $29.8 \mathrm{~mm}, \mathrm{BL}: 19.0 \mathrm{~mm}$ ) that exhibits moderate occlusal 428 wear. The DN 1111 a molar is also a complete crown (ML: $25.5 \mathrm{~mm}$ ) with moderate occlusal 429 wear but is set within a partially mechanically processed aggregation of indeterminate 430 postcranial fragments. As isolated teeth the specimens cannot be confidently attributed below the 431 generic level. Both specimens are consistent in cusp morphology, central cavity complexity and 432 overall size with extant comparatives and fossil Connochaetes sp. specimens from Swartkrans 433 Members 1 Hanging Remnant (e.g., SK 2482, 3008, 3102, 14120x) (linear metrics in Vrba, 434 1976). 
442 Referred specimens. DN 2790, right horn core; DN 4778, right horn core.

444 Description. Two partial right horn cores, representing two adult individuals, are attributed here to the genus Damaliscus. The most complete of the cores, DN 2790, preserves the pedicle 446 (infiltrated by an extensive sinus) to approximately $3 / 4$ of the body of the core, which exhibits a 447 small amount of torsion approaching the broken margin (Figure 6A). The base of DN 2790 core 448 is mediolaterally compressed (AP: $35.3 \mathrm{~mm}$, ML: $26.3 \mathrm{~mm}$ ) and there is a deep medial groove on 449 the body. The DN 4778 specimen preserves the body of the core in two articulating pieces, with 450 a third associated fragment lacking a clear contact point. While mechanical preparation damage 451 to DN 4778 prohibits confident metric comparison it exhibits analogous mediolateral 452 compression to the DN 2790 specimen.

453

454 Both the DN cores exhibit similar size, curvature and mediolateral compression to extant 455 Damaliscus dorcas comparative specimens and the SK 14206 specimen attributed to Damaliscus 456 cf. dorcas by Vrba (1976) (ML: 24.0 mm). Both Main Quarry specimens contrast with 457 previously described Damaliscus niro Hopwood, 1936 horn cores (including the Swartkrans 458 Member 2 specimen SK 2862) in size (e.g., SK 2862, AP: 44.0 mm, ML: 36.0 mm; Vrba, 
459 1976; published metrics from Olduvai and Cornelia in Gentry and Gentry, 1978), the onset of

460 torsion and the absence of transverse ridging (see also Cooke, 1974; Gentry, 2010). Although

461 these two specimens are morphologically close to $D$. dorcas, we agree with Gentry (2010: 786)

462 that a comprehensive revision of smaller Damaliscus from Pleistocene localities is critical before 463 attributing specimens like the Main Quarry horn cores to a species within the genus.

464

465

466

467

468

469

470

471

472

473

474

475

476

477

478

479

480

481
Genus MEGALOTRAGUS van Hoepen, 1932

Type species Megalotragus priscus Broom, 1909

Megalotragus sp.

Referred specimens. DN 748a, right M2; DN 748b, right M3; DN 856, left M2 (?); DN 4807, left M2.

Description. Four isolated alcelaphin maxillary molars exhibit dental dimensions that exceed extant Connochaetes comparatives with analogous occlusal wear and are consistent with fossil specimens attributed to the extinct genus Megalotragus. The two associated right molars (DN 748a, b) preserve complete crowns (DN 748a ML: 27.9 mm, BL: $19.2 \mathrm{~mm}$; DN 748b ML: 36.0 mm, BL: $19.4 \mathrm{~mm}$ ) and moderate-heavy occlusal wear (Figure 6B). Both DN 4807 and DN 856 are left M2s (with the DN 856 position in the toothrow only tentative) with moderate occlusal wear. While DN 4807 is missing the lingual enamel surface and is somewhat distorted, DN 856 preserves a nearly complete probable M2 crown (ML: $31.6 \mathrm{~mm}$, BL: $24.4 \mathrm{~mm}$ ) (with regluing 
482 and minor enamel damage). All four of these specimens are directly comparable in size and cusp

483 morphology to Megalotragus maxillary remains from Swartkrans Member 1 Hanging Remnant 484 (e.g., SK 2245, 2432, 3031) and Member 2 (e.g., SK 14120, 14218) (linear metrics in Vrba, 485 1976).

486 487

Alcelaphini gen. et sp. indet.

Referred specimens. DN 3, left deciduous P3; DN 41, left maxillary molar; DN 42, left maxillary molar (associated with DN 41); DN 82, left M3; DN 90, left deciduous P3; DN 255, 492 horn core fragment; DN 259, right m1; DN 309, left M1 or M2; DN 446, right m1; DN 475, right 493 deciduous p4; DN 529, right mandible with deciduous p3-p4; DN 719, right P3; DN 722, right $\mathrm{m} 1$ or $\mathrm{m} 2$; DN 831, right (?) horn core fragment; DN 837, mandible fragment; DN 863, cranial 495 fragment; DN 878, horn core fragment; DN 1001, left (?) horn core fragment; DN 1006, right deciduous p3; DN 1007, left m3; DN 1013, right horn core fragment; DN 1015, left mandible with deciduous p2-p4; DN 1021, right P3; DN 1025, deciduous P4; DN 1026, left m1 or m2; DN 1043, horn core fragment; DN 1061, left M2; DN 1065, right deciduous p3; DN 1099, left (?) 499 horn core fragment; DN 1143, left mandible with deciduous p2-p4; DN 1156, indet. side M2 or 500 M3; DN 2053, horn core pedicle fragment; DN 2157, right M1 or M2; DN 2161, horn core tip 501 fragment; DN 2168, tooth fragment; DN 2854, right m3; DN 2992, left mandibular molar 502 fragment; DN 4321, horn core fragment; DN 4466, right deciduous p4; DN 4514, right 503 deciduous p4; DN 4526, left m3; DN 4647, molar fragment; DN 4653, left mandible with p3-p4; 504 DN 4779, right M3; DN 4780, left m3. 
506 Description. Because of either incomplete preservation and/or the metric and morphological

507 overlap in the isolated dentition of extant and extinct alcelaphin genera and species, a total of 45

508 Main Quarry specimens could not be confidently attributed below the level of the Tribe. Within

509 this sample, 11 specimens (DN 259, 529, 722, 863, 878, 1099, 1156, 2157, 2161, 2992, and

5104653 ) are derived from minimally four larger size class III individuals (e.g., within the size range

511 of extant Connochaetes or larger); all adults excepting DN 529, which is an extremely young

512 individual with the deciduous premolars just erupting. The remaining specimens are derived

513 from minimally nine larger class II and smaller class III alcelaphin individuals (e.g., within the

514 size range of extant Damaliscus and Alcelaphus), including at least seven immature individuals

515 retaining their deciduous dentition (e.g., DN 1015; Figure 6C).

516

517 At present we include in this group five partial horn cores that may ultimately be attributable to

518 the generic or specific level; however, the paucity of horn cores from penecontemporanous South

519 African fossil deposits (particularly relative to the eastern African record) limits our ability to

520 confidently diagnose the specimens. The DN 4321 horn core exhibits a very large sinus within an

521 expanded pedicle, but supporting a very compressed core body that somewhat resembles the

522 morphology of extant Sigmoceras lichtensteinii Peters, 1849 (alt. Alcelaphus buselaphus

523 lichtensteinii sensu Gentry, 2010; Kingdon and Hoffman, 2013b). DN 1043 is a left, likely

524 immature horn core (AP: $39.3 \mathrm{~mm}$ ) that is derived from a smaller alcelaphin and somewhat

525 resembles the immature cores of extant Damaliscus lunatus Burchell, 1823 as well as the SK

52614008 indeterminate bovid horn core from the Member 1 Hanging Remnant. 
528 The three remaining horn cores (DN 255, 381, and 1013) appear to exhibit the same morphology

529 and are likely derived from the same alcelaphin species. The most complete of these, DN 1013,

530 is a $\sim 10 \mathrm{~cm}$ portion of a right horn core pedicle and body (Figure $6 \mathrm{D}$ ). The base of the horn core

531 lacks bossing as in extant Alcelaphus or Connochaetes, and the strong anticlockwise torsion

532 eliminates attribution to extant Damaliscus as well as the Swartkrans Member 1 SK $3211 \mathrm{~b}$

533 Numidocapra porrocornutus Vrba, 1971 specimen (sensu Gentry, 2010 after Vrba, 1997),

534 Parmularius braini Vrba, 1977, or Damaliscus gentryi Vrba, 1977 as represented by specimens

535 from Makapansgat Member 3. Amongst the previously described alcelaphin fossil horn cores,

536 the closest comparative specimen is the SK 14183 Beatragus sp. Heller, 1912 from Swartkrans

537 Member 2 (Vrba, 1976). When oriented relative to SK 14183, DN 1013 exhibits features

538 previously used by Vrba (1976) when attributing the SK specimen to Beatragus: anteroposterior

539 flattening of the core $\sim 3 \mathrm{~cm}$ above the base, anticlockwise torsion, a modest mesial keel,

540 foramina along the anterolateral border, and slight swelling on the posterolateral aspect (which is

541 compromised by surface damage) that may indicate the origin of a posterolateral keel. We note,

542 however, that the DN 1013 specimen is smaller (AP: $37.8 \mathrm{~mm}$, ML: $45.4 \mathrm{~mm}$ ) than the SK

54314183 Beatragus specimen (AP: $45.2 \mathrm{~mm}$, ML: $51.2 \mathrm{~mm}$ ) and the torsion is more exaggerated;

544 potentially reflecting ontogenetic, demographic or phylogenetic differences.

Tribe ANTILOPINI Gray, 1821

548

549

Genus ANTIDORCAS Sundevall, 1847

550

Type species Antidorcas marsupialis Zimmermann, 1780 
554 Referred specimens. DN 224, left adult male horn core; DN 879, left male horn core; DN 884, 555 right immature male horn core; DN 890, right adult male horn core; DN 938, left adult female 556 horn core; DN 990, right (?) immature male horn core; DN 995, left adult female horn core; DN 557 1014, right sub(?)adult female horn core; DN 1022, left adult male horn core; DN 1048, indet. 558 side female horn core; DN 1055, right (?) immature male horn core; DN 1058, left sub(?)adult 559 male horn core; DN 1060, right adult male horn core; DN 1068, left adult male horn core; DN 560 1071, left sub(?)adult male horn core; DN 2483a left adult female horn core; DN 2483b right 561 adult female horn core; DN 2789, indet. side male horn core; DN 3033, indet. side female horn 562 core; DN 3294, right immature male horn core; DN 4438, right adult female horn core; DN 563 4690, left immature male horn core (possible antimere of DN 884); DN 4698, indet. side female

564 (?) horn core; DN 4777, right male horn core; DN 4796, left adult female horn core.

Description. At present, this collection of 25 Antidorcas recki horn core specimens from at least 16 individuals is the largest described sample for the species from the Cradle (and outside the Olduvai Bed deposits) (Gentry, 1966; Gentry and Gentry, 1978; Cooke, 1996). It is also the most demographically diverse from the South African deposits, with minimally eight males (three 570 adult, two probable subadult, three immature) and eight females (seven adult, one probable 571 subadult) recorded in the sample. 
573 The morphology of the horn cores largely conform to the description of male and female $A$. recki

574 specimens from Olduvai (Gentry, 1966; Gentry and Gentry, 1978) and Bolt's Farm Pit 3 (Cooke,

575 1996) (and contrasts with extant Antidorcas marsupialis horn cores) in the vertical rise of the

576 horn core from the sinus-filled pedicle, degree of mediolateral compression, strong posterior

577 angulation within the short body, and a lack of lateral divergence or torsion (Figure 7A and 7B;

578 Table 4). The adult and immature male DN specimens contrast with those of Gazella vanhoepeni

579 Wells and Cooke, 1956 from the Makapansgat Member 3 deposits (e.g., M 412, 415, 2224, 2717,

$5808245,8384,9006,9026)$ in the less pronounced mediolateral compression, core body size, and

581 the sharper posterowards curvature in the core (Figure 7A). We do note, however, that none of

582 the male $\mathrm{DN}$ horn cores exhibit the strong transverse ridging present on the Bolt's Farm Pit 3

583 male cranium (UCMP 69521), which aligns the DN specimens with some of the noted A. recki

584 variants from Olduvai and Peninj described by Gentry and Gentry (1978: 429). The substantial

585 sample of female A. recki horn core specimens in the Main Quarry sample provides further

586 evidence for the presence of strong sexual dimorphism in this skeletal feature within the species

587 (Cooke, 1996). The DN female cores are substantially smaller, straighter, and exhibit a far more

588 rounded cross-section than the male counterparts (Figure 7B); consistent with the morphology of

589 the Bolt's Farm Pit 3 UCMP 80168 and 80169 specimens (Cooke, 1996; Table 4).

Antidorcas cf. recki

593 Referred specimens. DN 140, right indet. maxillary molar; DN 175, right m1 or m2; DN 308,

594 right m3; DN 401, left P4; DN 447, right m1; DN 989, right P3; DN 1002, right mandible with

595 p4-m2 (associated with DN 2283); DN 1034, right m1 or m2; DN 1054, right M1 or M2; DN 
596 1059, indet. side male (?) horn core; DN 1115, right immature horn core; DN 1116, right m3;

597 DN 1135, left P4; DN 2175, indet. side m1 or m2; DN 2270, left mandible with p4 and m2; DN 598 2271, right P4; DN 2283, right m3; DN 2307, right immature horn core; DN 2328, left p4; DN 599 2554, left M2; DN 2614, right mandible with deciduous p2-p4 and m1-m2; DN 3009, left P3; 600 DN 3287, right m2; DN 3346, left m1 or m2; DN 4185, right M2; DN 4290, right m3.

601

602 Description. In addition to the attributed Antidorcas recki horn cores, a collection of 26 603 Antidorcas craniodental specimens have also been recovered from the Main Quarry deposits. 604 This sample of isolated teeth display similar crown morphology with other previously attributed 605 Antidorcas recki dentition from Bolt's Farm (see above; Cooke, 1996), Kromdraai A (e.g., KA 606 964B, 1002, 1111, 1093) and dissimilar to both extant Antidorcas marsupialis Zimmerman, 1780 607 and the hypsodont Antidorcas bondi Cooke and Wells, 1951 specimens from Swartkrans 608 Member 2 (Vrba, 1976). Furthermore, most of these isolated specimens were recovered 609 interspersed within the decalcified Main Quarry sediments alongside the diagnostic $A$. recki horn 610 core specimens; and in the case of DN 3346 and 4185, were recovered from just adjacent to the

611 DN 3033 and 3294 horn cores. We do, however, recognise and support the caution expressed by

612 Gentry (2010) regarding the separation of remains of $A$. recki from early remains of $A$. bondi and 613 Antidorcas australis Hendey and Hendey, 1968/A. marsupialis. In keeping with a more 614 conservative approach to these fragmentary craniodental remains, we treat them as provisionally 615 attributable to $A$. recki.

616

617 
623 Referred specimen. DN 591, right $\mathrm{p} 3$.

625 Description. The single right mandibular third premolar is a complete crown (ML: $7.7 \mathrm{~mm}$, BL:

$6263.1 \mathrm{~mm}$ ) with only superficial occlusal wear. The tooth is very mesiodistally elongate, exhibiting 627 the gracile cusp morphology and weak-development of distal elements (e.g., hypoconid, 628 entoconid/entostylid barely developed and fused) that is similar to the equivalent tooth preserved 629 in the KA 710 Raphicerus campestris mandible from Kromdraai A (Vrba, 1976) and extant $R$. 630 campestris comparatives.

631

632

633

634

635

636

637

638

639 Referred specimens. DN 290, left mandible with deciduous p3; DN 400, right m2; DN 432, 640 right $\mathrm{m} 1$ (associated with $\mathrm{DN} 400$ ); DN 438, right mandible with m1-m3; DN 590, left M1 or 641 M2; DN 710, right mandible with deciduous p3; DN 857, left mandible with m3; DN 910, right 
642 mandible with m1-m3; DN 965, right mandible with deciduous p3; DN 1008, right mandible 643 with deciduous p3; DN 1046, left M1 or M2; DN 4773, left m2.

644

645 Description. The 12 mandibular specimens attributed here to Oreotragus are derived from at 646 least nine individuals (five adults with occluded third molars, four immature individuals 647 retaining their deciduous premolars). The more complete DN 438 (m2 MD: 12.0 mm, BL: 5.8 648 mm; m3 MD: 16.0 mm, BL: 5.7 mm; Figure 7C), DN 857 (m1 MD: 9.5 mm, BL: 6.2 mm; m2 649 MD: $11.8 \mathrm{~mm}, \mathrm{BL}: 6.4 \mathrm{~mm}$; 3 MD: $19.3 \mathrm{~mm}, \mathrm{BL}: 6.5 \mathrm{~mm}$ ) and DN 910 (m1 BL: $5.8 \mathrm{~mm}$; m2 650 MD: $13.3 \mathrm{~mm}, \mathrm{BL}: 6.5 \mathrm{~mm}$; $3 \mathrm{MD}: 15.4 \mathrm{~mm}, \mathrm{BL}: 6.5 \mathrm{~mm}$ ) specimens preserve relatively 651 complete corpora and molars. The dental measurements of the DN Oreotragus specimens place 652 them roughly in the narrow zone of overlap between the smaller-bodied fossil Oreotragus 653 populations from Gondolin GD 2 and the larger-bodied Oreotragus from Haasgat HGD and 654 Makapansgat Member 3 (see Adams, 2012a for comparative Oreotragus dental metrics). As 655 noted in Adams (2012), a comprehensive revision of the fossil record of the genus is essential to 656 establish the significance of the metric variability in Oreotragus across South African Plio657 Pleistocene deposits. 
666 Referred specimens. DN 111, right partial horn core and orbital margin; DN 2573, right partial

667 horn core; DN 4775, right partial horn core.

668

669 Description. The most complete of the reduncin horn core specimens attributed to Redunca cf. 670 fulvorufula is DN 111, which preserves the right horn core pedicle as well as part of the right 671 superior orbital margin and cranial vault. The two other right horn cores, while retaining less 672 adhering cranial vault portions preserve the same core morphology as DN 111. The angle of horn 673 core insertion, absence of sinuses in the pedicle, and development of the postcornual fossa are 674 consistent with members of the tribe, and the size, insertion angle and cross-sectional shape of 675 the core excludes attribution to genus Kobus Smith, 1840. Among extant and extinct Redunca 676 species, the DN specimens are smaller than, and exhibit more upright and rounder horn cores, 677 than both the extinct Redunca darti Wells and Cooke, 1956 from Makapansgat Member 3 (e.g., 678 M 446 [type specimen], M 453, M 461, M 464, M 783) and extant Redunca arundinum 679 Boddaert, 1785 comparative specimens (see also discussion of Redunca horn cores in Adams, 680 2006). The $\mathrm{DN}$ horn cores are similar in these morphological features to extant Redunca 681 fulvorufula and the Gondolin GD 2 Redunca sp. horn cores (Adams and Conroy, 2005; Adams, 682 2006), but are from distinctly smaller-bodied individuals than the population sampled in the 683 Gondolin GD 2 assemblage. Although the evolutionary relationships of South African Plio684 Pleistocene Redunca and the diversity of reduncins during the Neogene remain unresolved (see 685 Adams and Conroy, 2005; Adams, 2006, 2012; Adams et al., 2010; Gentry, 2010), the 686 morphology expressed by the Main Quarry specimens is most comparable with extant $R$. 687 fulvorufula; a species present in the Cradle by at least the mid-Pleistocene (e.g., Gladysvale 
et

al., 2002).

689

690

691

692

693

694

695

696

697 Referred specimens. DN 120, right mandible with p2-m3; DN 163, left m3; DN 164, left m1;

698

699

700

701

702

703

704

705

706

707

708

709

710
Tribe TRAGELAPHINI Blyth, 1863

Genus TRAGELAPHUS de Blainville, 1816

Type species Tragelaphus scriptus Pallas, 1766
Tragelaphus sp.

DN 165, left m2; DN 399, right p3; DN 1011, left M1; DN 1027, associated right p3, p4, and m1-m2 in a mandibular corpus; DN 2788, left maxilla with deciduous P4-M2; DN 4112, right $\mathrm{m} 1$ or $\mathrm{m} 2$.

Description. The Drimolen Main Quarry Tragelaphus sample includes at least two different species. At least one species of large Tragelaphus is represented by the DN 399 and DN 2788 specimens. The crown of the DN 399 p3 is complete and unworn, but the roots are incompletely formed. The crown is brachydont and the morphology of the paraconid, metaconid and entoconid are consistent with extant Tragelaphus strepsiceros Pallas, 1766 comparative specimens. The DN 2788 maxilla retains the deciduous p4 and the M2 is just reaching the occlusal plane. Like the DN 399 specimen, the brachydonty and loph morphology is consistent with the genus, and size of the dentition is within the range of extant $T$. strepsiceros. Although these two specimens could potentially be derived from the same immature individual, we consider them as 
711 representing minimally two different individuals based on provenance: the DN 399 specimen

712 was recovered from decalcified sediments (-2.3 m below datum; MBD) whereas the DN 2788

713 specimen was mechanically recovered from a surface-recovered ex situ calcified sediment block.

715 The remaining specimens are derived from at least one smaller species of Tragelaphus, likely

716 representing minimally four individuals of Tragelaphus pricei Wells and Cooke, 1956 or the

717 Tragelaphus scriptus lineage; however, lacking horn cores we cannot provide a more specific

718 attribution. The most complete of these specimens are the DN 120 and DN 1027 right mandibles

719 (Figure 6C). Both specimens exhibit similar dental metrics, corpus depths, premolar morphology

720 (including paraconid-metaconid fusion on the $\mathrm{p} 4$ ) and buccal lophid rounding to the $T$. pricei

721 holotype (M 18) and paratype (M 17, M 19) specimens from the Makapansgat Member 3

722 deposits (Wells and Cooke, 1956). The evolutionary relationships between the South African $T$.

723 pricei and other smaller fossil Tragelaphus (e.g., Tragelaphus nkondoensis Geraads and Thomas,

724 1994) and extant T. scriptus is not resolved (see Gentry, 2010), and further assessment of the

725 African record may eventually permit a more specific diagnosis of the Main Quarry specimens.

Referred specimens. DN 1193, right $\mathrm{m} 1$ or $\mathrm{m} 2$ with associated tooth fragment in matrix.

731 Description. Two associated craniodental specimens (catalogued as DN 1193) are

732 morphologically consistent with a large-sized tragelaphin but are not attributable to generic level.

733 The associated tooth fragment is a partial molar (probably a lower buccal loph), while the more 
734 complete tooth is a damaged right lower molar lacking the lingual enamel surface. The angled

735 buccal lophids and brachydonty of the lower molar is consistent with the tribe, and the size

736 places the specimen within the range of extant Tragelaphus strepsiceros and smaller

737 Taurotragus oryx individuals.

738

739

740

Bovidae gen. et sp. indet.

741

742 Referred specimens. 538 specimens (see Supplemental Table 1)

743

744 Description. The majority of the indeterminate bovid specimens from the Main Quarry deposits

745 are postcranial elements $($ NISP $=365$ ), with only 173 craniodental specimens (primarily

746 nondiagnostic enamel fragments, mandibular incisors or poorly preserved horn core fragments)

747 not attributed below the Family level (Supplemental Table 1). Although these remains are

748 undiagnostic, we would note that there is no indication of additional bovid taxa in the Main

749 Quarry deposits beyond those established by the other referred specimens above. The one

750 exception is the DN 647 partial left maxillary molar, which exhibits hypsodonty consistent with

751 alcelaphins, but also resembles some of the smaller ovibovin remains potentially attributable to

752 Makapania Wells and Cooke, 1956 from Swartkrans Member 1, Gladysvale, and Haasgat HGD

753 (Vrba, 1976; Lacruz et al., 2002; Adams, 2012a).

754

755

756

Family GIRAFFIDAE Gray, 1821 
Giraffidae gen. et sp. indet.

759

760 Referred material. DN 1097, right humerus.

761

762 Description. The DN 1097 specimen is an extremely large right cetartiodactyl humerus that 763 preserves the medial portion of the condyle, supracondylar region, and the diaphysis to the distal764 most portion of the humeral crest (Figure 8A). Although no standard metrics could be gathered, 765 the preserved length of the specimen is $\sim 26 \mathrm{~cm}$ and the length of the medial epicondyle to

766 midsagittal of the condyle is $\sim 6.5 \mathrm{~cm}$, indicating an approximate epicondylar width of $\sim 12-13$

$767 \mathrm{~cm}$. In addition to the size of the preserved specimen, several morphological features align DN

7681097 to extant giraffid comparative specimens (e.g., Giraffa camelopardalis Linnaeus, 1758) to

769 the exclusion of a large bovid (e.g., extant Syncerus caffer Sparrman, 1779). The supracondylar

770 diaphysis is ovoid (anteroposteriorly compressed, mediolaterally wide) rather than triangular

771 from a more robust humeral crest. The medial articular surface of the condyle is

772 anteroposteriorly flattened and cylindrical, and lacks a strongly developed sagittal ridge laterally.

773

774 Unfortunately, there is a paucity of fossil giraffid postcranial from the South African 775 palaeokarstic deposits, with only small collections described from Makapansgat Member 3 and 776 the Swartkrans Members 1-3 deposits (Reed, 1996; Watson, 1993). Only a single humerus 777 attributed to the extinct Sivatherium Falconer and Cautley, 1836 has been described from

778 Swartkrans Member 1 Hanging Remnant (SK 3172), but this left humerus preserves only the 779 non-overlapping proximal region. The penecontemporaneous eastern African record is more 
780 substantial, with postcranial samples from Koobi Fora, Olduvai, Omo-Shungura and Laetoli

781 (Harris, 1976; Leakey and Harris, 1987; Harris, 1991; Robinson, 2011). The features that would

782 allow for confident attribution of the DN specimen as either giraffine or sivatherine (e.g.,

783 elongation of the diaphysis, relative compression and width of the distal epiphyses) cannot be

784 ascertained in the preserved state; and the humeri of Plio-Pleistocene giraffid species overlap

785 significantly in simple linear metrics (Leakey and Harris, 1987; Harris, 1991; Robinson, 2011).

786 Given these limitations, we treat this specimen as indeterminate below the Family level.

787

788

789

790

791

792

793

794

795

796

797

798

799

800

801

802
Family SUIDAE Gray 1821

Suidae gen. et sp. indet.

Referred material. DN 2850, right third metatarsal.

Description. The DN 2850 specimen is a nearly complete right third metatarsal from a juvenile suid, preserving a notably immature proximal articular surface (missing part of the medial articular surface) and an unfused distal metaphyseal surface (Figure 8B). The diaphysis of the element is visibly robust (ML: $12.1 \mathrm{~mm}$, dorsoventral depth: $10.1 \mathrm{~mm}$ ) given its overall length (53.2 mm). Metric comparisons of the proximal articular and distal metaphyseal surfaces of DN 2850 against the third metatarsals of extant Phacochoerus aethiopicus Pallas, 1766 and Potamochoerus porcus Linnaeus, 1758 place this very immature element outside or just within the measured ranges of even fully adult $P$. aethiopicus and $P$. porcus individuals with complete 
803 proximal articular surface development and distal metaphyseal fusion (Table 5). The size of the

804 specimen at its developmental stage would therefore seemingly preclude attribution to either of

805 these extant genera.

806

807 Comparable fossil suid third metatarsals are extremely rare within African Plio-Pleistocene

808 deposits (Bishop, 1994); however, a partial right third metatarsal of Metridiochoerus andrewsi

809 (G 8105) has been described from the Gondolin GD 2 assemblage (Adams, 2006). The G 8105

810 specimen only preserves the proximal articular surface and part of the diaphysis and is derived

811 from a more developmentally mature individual (or full adult), and the single comparable

812 measurement reflects the larger body size of the species compared to the extant suids (Table 5).

813 While the overall shape of the proximal articular surface and robusticity of the diaphysis appears

814 shared between DN 2850 and G 8105, the significant ontogenetic differences prohibit confident

815 attribution of the Main Quarry specimen to the same genus or species based solely on these

816 broad similarities. Similarly, while other suid genera (e.g., Notochoerus, Kolpochoerus) are less

817 frequently recovered than remains of Metridiochoerus in South African Plio-Pleistocene

818 deposits, we also lack equivalent postcrania for these lineages to allow for direct comparisons. At

819 present, we can only state that this specimen is derived from an extinct suid lineage that

820 exhibited larger adult body size than extant or attributed fossil Phacochoerus or Potamochoerus.

821

822

823

Order PERISSODACTYLA Owen, 1848

824

Family EQUIDAE Gray, 1821

825

Genus EQUUS Linnaeus, 1758 
830 Referred material. DN 3424, left distal tibia; DN 4525, intermediate phalanx; DN 4781, partial 831 ungual phalanx.

833 Description. The DN 3424 specimen preserves part of the distal metaphysis and articular surface

834 from a left tibia, from the medial malleolus to the midline. There is no indication of persistence

835 of a metaphyseal line indicating full closure of the distal growth plate and skeletal maturity of the

836 element. Unfortunately, no standard metrics could be taken from the specimen to facilitate

837 comparisons, but the element is directly comparable to extant E. quagga ssp. tibiae in size and 838 morphology and is visibly smaller than the Equus capensis Broom, 1909 distal tibiae previously 839 described from Swartkrans Members 1 Lower Bank (SKX 9596) and 2 (SKX 2390) (Churcher 840 and Watson, 1993), as well as the Equus sp. specimen from the Haasgat HGD deposits (HGD 841 1015; Adams, 2012a).

842

843 The DN 4525 intermediate phalanx preserves the proximal epiphysis (ML: $45.9 \mathrm{~mm}$, 844 dorsoventral depth: $33.0 \mathrm{~mm}$ ) and most of the diaphysis, but lacks the distal articular surface and 845 some of the anterior face of the distal metaphyseal/diaphyseal region. The articular surfaces as 846 preserved appear fully mature, there is no indication of a persistent metaphyseal line. As is the 847 case with the DN 3424 tibia, the intermediate phalanx is consistent with extant E. quagga ssp. 848 intermediate phalanges in size and morphology and smaller than previously described $E$. 
849 capensis specimens from Swartkrans Member 3 (SKX 39182: proximal ML: 50.0 mm [min.],

850 proximal dorsoventral depth: $36.0 \mathrm{~mm}$ [min.]) and Haasgat HGD (HGD 1099, proximal ML:

$85153.5 \mathrm{~mm}$, proximal dorsoventral depth: $33.8 \mathrm{~mm}$ ) (Churcher and Watson, 1993; Adams, 2012a).

852

853 The DN 4781 specimen preserves only a partial proximal articular facet and part of the volar

854 surface of an equid ungual phalanx. The specimen is visibly larger than the hipparionin ungual

855 phalanges previously described from Swartkrans Member 1 (SKX 9166), Member 2 (SKX

856 2626), and Gondolin GD 2 (G 4218) (Churcher and Watson, 1993; Adams, 2006), and there is no

857 indication of multiple nutrient foramina on the volar surface or posterior projection of the

858 articular surface consistent with that tribe. The specimen appears to fall within the size range of

859 extant E. quagga ssp. comparative specimens, and was recovered in close spatial proximity to

860 the DN 3424 and 4525 specimens (see below). Collectively, this supports allocating this

861 specimen to both E. quagga ssp. and potentially to the same individual as the other equid

862 remains from the Main Quarry decalcified deposits.

863

864

865

Order PROBOSCIDEA Illiger, 1811

866

Family ELEPHANTIDAE Gray, 1821

867

868

Elephantidae gen. et sp. indet.

869

870 Referred material. DN 4335, maxillary incisor fragment.

871 
872 Description. A single tusk fragment (DN 4335) recovered from the decalcified sediments can be

873 attributed to an indeterminate genus and species of elephantid (Figure 9A). The recovery of this

874 specimen, while relatively rare within other palaeokarstic deposits from the region, is not

875 unexpected given the presence of minimally two separate elephantid tusk portions within the

876 unexcavated calcified sediments of the Drimolen Main Quarry. The fragment exhibits both

877 surface pitting and break-edge rounding, and it is uncertain whether the specimen preserves the

878 most external, cortical enamel lamina or a more internal layer of enamel. The inner surface of the

879 fragment exhibits fresh exposure of enamel that highlights the light longitudinal banding of the

880 enamel, which under magnification is matched on the external, pitted surface of the specimen.

881 The DN specimen is similar in laminar enamel thickness and suggested cross-sectional area and

882 shape to the Swartkrans Member 1 Lower Bank specimens that have been previously attributed

883 to Elephas sp. Linnaeus, 1758 (SKX 45691, 45692b; Watson, 1993); however, as a single tusk

884 fragment we remain conservative in our attribution until further remains are recovered.

885

886

887

Order HYRACOIDEA Huxley, 1869

888

Family PROCAVIIDAE Thomas, 1892

889

Genus PROCAVIA Storr, 1780

890

Type species Procavia capensis Storr, 1780

891

892

Procavia sp.

893 
894 Referred material. DN 552, left $\mathrm{m} 1$ or m2; DN 2365b, right I1; DN 2971, right and left I1 895 (antimeric); DN 3072, right distal femur; DN 4219, right I1.

896

897 Description. In contrast to the faunal samples recovered from most other South African 898 palaeokarstic localities and deposits there is only an extremely small sample of hyrax remains at 899 the Drimolen Main Quarry deposits (see Churcher, 1956; Brain, 1981). The collection of six total 900 specimens are largely isolated central incisors. The antimeric pair (DN 2971) are most likely 901 from a male individual given the sharp, centrally-positioned keel, while the DN 2365b and 4219 902 specimens exhibit the more rounded contour and mesial position of the central keel consistent 903 with being from females (Churcher, 1956). None of the recovered teeth are metrically consistent with Procavia transvaalensis Shaw, 1937 (see comparative measurements in Churcher, 1956). Similarly, the DN 3072 distal femur is homologous to extant Procavia capensis Pallas, 1766 comparative specimens and visibly smaller than the $P$. transvaalensis distal femur from Haasgat HGT (HGT 1004; Adams, 2012a). As the composition of the sample does not allow us to diagnose whether the sample is derived from the extinct Procavia antiqua Broom, 1934 (see also Schwartz, 2007) and/or extant P. capensis, we can only attribute the Main Quarry specimens to a species of Procavia that is not P. transvaalensis.

911

912

913 Order LAGOMORPHA Brandt, 1855 
921 Referred material. DN 2823, right mandible preserving the p3-m2.

922

923 Description. Only one of the 38 identified leporid remains could be identified as representing as 924 species of Pronolagus in the Drimolen Main Quarry deposits. The overall size of the specimen is 925 significant smaller than in extant Lepus capensis Linnaeus, 1758, and the p3 exhibiting both 926 anterior reentrants and no evidence of the posteroexternal reentrant extending nearly to the 927 lingual border of the tooth as in Lepus. Amongst extant analogues, the overall mandibular 928 morphology is similar to Pronolagus rupestris Smith, 1834 but the dentition and corpus is 929 somewhat smaller than both male and female $P$. rupestris comparatives. Given the currently 930 limited data on the South African leporid record (Winkler and Avery, 2010), we retain the

931 specimen at the generic level pending a more comprehensive review of the South African Plio932 Pleistocene lagomorphs.

933

934

935 Leporidae gen. et sp. indet.

936

937 Referred material. DN 771, right immature proximal tibia; DN 1083, left calcaneus; DN 2104, 938 right calcaneus; DN 2155, left distal scapula; DN 2256, left immature proximal tibia; DN 2330, 939 left mandibular corpus; DN 2333, right maxillary premolar or molar; DN 2341, left calcaneus; 
940 DN 2342, left calcaneus; DN 2365c, left distal humerus; DN 2571, right immature distal femoral

941 epiphysis; DN 2715a, right distal humerus; DN 2715b, left proximal ulna; DN 2736, right

942 immature calcaneus; DN 2798, right proximal tibia; DN 2800, right immature distal femoral

943 epiphysis; DN 2805, right immature distal femoral metaphysis (articulates with DN 2800); DN

944 3059, left immature distal femoral epiphysis; DN 3304, left distal scapula; DN 4114, left

945 proximal ulna; DN 4116, left distal humerus; DN 4118, left calcaneus; DN 4120, associated set

946 of three lumbar vertebrae and sacrum; DN 4127, right immature proximal ulnar metaphysis; DN

947 4208, right distal humerus; DN 4225, left distal humeral metaphysis; DN 4226, left distal tibia;

948 DN 4227, right distal scapula; DN 4228, left proximal ulna; DN 4229, partial edentulous

949 maxilla; DN 4257, left immature calcaneus; DN 4381, left immature distal femoral epiphysis;

950 DN 4399, indet. side immature distal femoral epiphysis; DN 4531, left proximal tibial 951 metaphysis.

952

953 Description. The indeterminate leporid sample includes 34 numbered specimens (representing

95436 total elements). Other than fragmentary and indeterminate craniodental remains (DN 2333

955 and DN 4229), the current collection is comprised of postcranial remains from what are likely

956 two different species. The majority of the remains are derived from a lagomorph somewhere in

957 body size between extant Lepus capensis and Pronolagus rupestris. A smaller lagomorph that

958 had adult and immature postcranial elements smaller than adult extant $P$. rupestris is represented

959 by DN 2104, 2155, 2715a \& b, 2800, 2805, 3059, 4120, and 4228.

960

961

962

Order RODENTIA Bowdich, 1821 
963

964

965

966

967

968

969

970

971

972

973

974

975

976

977

978

979

980

981

982

983

984

985
Family HYSTRICIDAE Fischer de Waldheim, 1817

Genus HYSTRIX Linnaeus, 1758

Type species Hystrix cristata Linnaeus, 1758

Referred material. DN 2760, left maxillary molar (M2?)

Hystrix sp.

Description. Only a single identifiable left maxillary molar can be attributed to an indeterminate species of porcupine (Figure 9B). The presence of both mesial and distal interstitial wear facets indicate that the specimen is either an M1 or M2; we favour the latter based on both the size and occlusal outline but cannot confidently attribute the position. Metrically, the specimen (MD: 8.2 mm, BL: $9.3 \mathrm{~mm}$ [min. given minor enamel flaking]) falls within the range of extant Hystrix africaeaustralis Peters, 1852 maxillary M1s and M2s and is smaller than both Hystrix makapanensis Greenwood, 1958 and Xenohystrix crassidens Greenwood, 1955 (Adams, 2012b). We would note, however, that the current metric range for H. makapanensis M1s and M2s is based on an extremely small sample from the Gondolin GD 2 assemblage (e.g., derived from two individuals; Adams, 2012b). As an isolated tooth lacking other diagnostic features we elect to retain the specimen at the generic level.

Order TUBULIDENTATA Huxley, 1872

Family ORYCTEROPODIDAE Gray, 1821 
986

987

988

989

990

991 Referred material. DN 1062, right proximal radius.

992

993

994

995

996

997

998

999

1000

1001

1002

1003

1004

1005

1006

1007 Fauna from the site has been recovered from both calcified and decalcified deposits in the Main

1008 Quarry using a variety of techniques over the years. A small portion of the collections from the
Genus ORYCTEROPUS Geoffroy Saint-Hilaire, 1796

Type species Orycteropus afer Pallas, 1766

Orycteropus cf. afer
Description. The DN 1062 right proximal radius preserves a nearly complete head with articular surfaces and radial tuberosity, but very little diaphysis distal to the tuberosity (Figure 9C). Although there is minor abrasion damage to the cortex around the radial head, the minimum linear dimensions are $17.1 \mathrm{~mm}$ mediolaterally and $12.5 \mathrm{~mm}$ dorsoventrally. The articular surface morphology of the specimen is diagnostically orycteropodid (to the exclusion of similarly sized carnivores, primates, Hystrix and Smutsia [Order Philodota]) in the well-developed medial articular facets for contact with the lateral coronoid process of the ulna (Figure 9C). The DN specimen is identical to extant Orycteropus afer radii available to us for direct comparison in both morphology and size, and exhibits excellent joint congruence with the capitulum of the Orycteropus cf. afer distal humerus from Swartkrans Member 1 (SKX 14261) (Lehmann, 2004).

\section{Biochronology}


1009 early 1990s was developed from blocks recovered from the lime miners dumps just outside the

1010 Main Quarry. While these blocks have always been assumed to come from the Main Quarry

1011 deposits due to their proximity, the recent excavation of a newer, older $(\sim 2.6 \mathrm{Ma}) 50 \mathrm{~m}$ west of

1012 the Main Quarry (the Drimolen Makondo; Rovinsky et al., 2015; Herries et al., in review) does

1013 mean that this ex situ material could be mixed from more than one age of deposit. However,

1014 these two different deposits are not stratigraphically intertwined as is the case for deposits like

1015 Members 4 and 5 at Sterkfontein (Herries and Shaw, 2011) or Swartkrans Members 1-3 (Herries

1016 and Adams, 2013). This is currently no indication that similarly-aged Pliocene deposits exist in

1017 the Main Quarry itself.

1018

1019 Although there is notable diversity in the recovered Drimolen Main Quarry faunas, the majority

1020 of the specimens provide limited biochronological data for interpreting the age of the deposits.

1021 As is typical for South African palaeokarstic deposits in the region, the recovery of Equus cf.

1022 quagga ssp. from the in situ deposits indicates that at least part of the assemblage formed after

1023 2.33 Ma given the first appearance of the genus in African early Pleistocene deposits (Geraads,

1024 Raynal \& Eisenmann, 2004). The remainder of the ungulate specimens identified from the Main

1025 Quarry are either not specifically attributable, are members of long-surviving Plio-Pleistocene

1026 lineages, or have poorly-secured first appearance (FAD) and last appearance dates (LAD) in

1027 South Africa. The largest bovid sample in the assemblage, Antidorcas recki, has been recovered

1028 from eastern and South African deposits spanning the late Pliocene (e.g., Shungura Formation B-

1029 H; Gentry, 2010; McDougall et al., 2011; Brown et al., 2013) to the $>1.07 \mathrm{Ma}$ (or $<0.780 \mathrm{Ma}$ )

1030 Olduvai Bed IV (Tamrat et al., 1995) and the 1.07-0.780 Ma Elandsfontein deposits (Gentry,

1031 2010; Braun et al., 2013). The differences in the transverse ridging of the horn cores with the 
1032 previously described Bolt's Farm Pit 3 specimens may or may not reflect a temporal difference

1033 in depositional age.

1034

1035 Although this analysis has not addressed the non-hominin primates from the Drimolen Main

1036 Quarry, data reported in Nieuwoudt (2014) and reproduced in Table 1 suggests a fairly

1037 homogenous sample of cercopithecoids relative to other nearby early Pleistocene palaeokarstic

1038 deposits that typically record greater taxonomic diversity (Brain, 1981; Jablonski and Freedman,

1039 2010). The specifically attributable DMQ specimens have been allocated to either the extinct

1040 papionin subspecies Papio hamadryas robinsoni Freedman, 1957 (alt. Papio robinsoni; Gilbert

1041 et al., 2015) or the extinct colobine species Cercopithecoides williamsi Mollett, 1947. Both of

1042 these species have FADs in the late Pliocene (a constrained FAD for Papio somewhat less clear,

1043 see Jablonski and Frost, 2010 and Gilbert et al., 2015) and are common in post 2 Ma early

1044 (potential to mid-) Pleistocene South African deposits (e.g., Swartkrans, Sterkfontein Member 5,

1045 Kromdraai, Cooper's D, Gladysvale; Jablonski and Frost, 2010). As such, neither primate

1046 provides strong biochronological constraints on the depositional age of the Main Quarry deposits

1047 beyond being consistent with species recovered from other nearby early Pleistocene localities

1048 (e.g., Sterkfontein Members 4 and 5, Swartkrans Members 1-3, Kromdraai A and B) (Brain,

1049 1981; Jablonski and Frost, 2010).

1050

1051 The carnivoran specimens provide a more constrained depositional age. Remains of the genus

1052 Chasmaporthetes have been recovered across African localities, with C. nitidula described from

1053 South African deposits ranging from Sterkfontein Jacovec Cavern and Members 2 and $4(<2.46-$

1054 2.01 Ma; Herries et al., 2013) to as late as Swartkrans Member 3 (sometime between 1.3-0.6 Ma; 
1055 Herries, Curnoe \& Adams, 2009). However, Lycyaenops silberbergi has been recovered from a

1056 far narrower range of terminal Pliocene and early Pleistocene deposits of Laetoli (as Lycyaenops

1057 cf. L. silberbergi; Werdelin and Dehghani, 2011) in East Africa and Sterkfontein in South Africa

1058 ( 3.8-2.02 Ma; Turner, 1990, 1997; Werdelin and Lewis, 2005; Werdelin and Peigné, 2010;

1059 Herries and Shaw, 2011; Herries et al., 2013). A single mandibular specimen (SK 300) of

1060 Lycyaenops silberbergi has been described from Swartkrans Member 1 (Ewer, 1955b), and

1061 although questions over provenience has been raised it is still considered derived from these

1062 deposits (see discussion in Turner, 1987b); this effectively establishes an LAD for the species

1063 within these deposits of 1.96-1.80 Ma (Pickering et al., 2011a; Herries and Adams, 2013).

1064

1065 The identification of Dinofelis cf. barlowi from the DMQ also argues for a late Pliocene-early

1066 Pleistocene deposition. This apparently endemic South African machairodont has been

1067 definitively recovered from a temporally narrow range of deposits spanning approximately 2.7-

1068 1.98 Ma (Werdelin and Lewis, 2001; Lacruz, Turner \& Berger, 2006; Herries, Curnoe \& Adams,

1069 2009; Werdelin and Peigné, 2010; Herries and Shaw, 2011; Pickering et al., 2011b; Kuhn et al.,

1070 2012). What cannot be determined at this point is the biological relationship of this specimen to

1071 the previously described Dinofelis aff. piveteaui specimens, as no maxillary canine was

1072 recovered or described in association with those craniodental remains. As discussed by O'Regan

1073 and Menter (2009), the basis for classifying the DMQ Dinofelis remains as D. aff. piveteaui is

1074 based largely on P4 morphology. The protocone of the DN 1012 P4 is reduced; not as reduced as

1075 D. piveteaui specimens from Kromdraai A or Motsetse but yielding a buccolingually-narrower

1076 tooth than is present in D. barlowi. Simultaneously, the P4 metastyle blade is only slightly

1077 mesiodistally elongated relative to D. barlowi and lacks the elongation exhibited by South 
1078 African D. piveteaui P4 specimens. As with much of the anatomy of fossil taxa established from

1079 small sample sizes, it is difficult at present to establish whether these P4 features reflect sexual

1080 dimorphism, individual, or chronological variation within either D. barlowi or D. piveteaui. And

1081 while further craniodental specimens could ultimately link the DN 2791 canine with these other

1082 DMQ Dinofelis remains, there is no morphological affinity to $D$. piveteaui maxillary canines to

1083 support treating the specimen as derived from the same population.

1084

1085 Ultimately, if these previously described remains cannot be accommodated with either species 1086 sensu stricto we posit four potential interpretations of the DMQ Dinofelis material assigned to $D$.

1087 aff. piveteaui by O'Regan and Menter (2009) that will require further analysis to test whether: 1)

1088 they represent a derived D. barlowi; 2) they represent a primitive D. piveteaui sensu stricto; 3)

1089 they are derived from a discrete population undergoing anagenesis from a more primitive

1090 Dinofelis (e.g., D. barlowi [O'Regan and Menter, 2009] or Dinofelis aronoki [Werdelin and

1091 Lewis, 2001]) to D. piveteaui in the early Pleistocene; or 4) they represent a separate, previously

1092 unrecovered species of Dinofelis in the African record (which we view as less likely). If the

1093 DMQ Dinofelis aff. piveteaui remains represent a novel species, they would ultimately contribute

1094 little to interpreting deposit biochronology. As D. barlowi does not occur in South African

1095 deposits after 1.98 Ma, if the DMQ Dinofelis aff. piveteaui remains are a derived D. barlowi they

1096 would likely indicate deposition after $1.98 \mathrm{Ma}$ - but would similarly lack an established FAD or

1097 LAD. Finally, given the recovery of the D. piveteaui type specimen from the (tentatively dated)

1098 1.89-1.63 Ma Kromdraai A deposits (Herries, Curnoe \& Adams, 2009, Gilbert, Frost \& Delson,

1099 2016) and in east Africa by 1.61 Ma (Werdelin and Lewis, 2005; McDougall et al., 2011), then 
1100 the DMQ Dinofelis aff. piveteaui specimens would suggest a depositional date prior to $\sim 1.6 \mathrm{Ma}$

1101 and/or the Kromdraai A assemblage.

1102

1103 In sum, the DMQ faunal assemblage includes species only occupying the South African

1104 landscape after 2.33 Ma (Equus cf. burchelli ssp.), and includes the remains of carnivore species

1105 whose currently reconstructed LADs within the early Pleistocene indicate that at least some of

1106 the deposits formed prior to (or near) 2.02 Ma (Lycyaenops silberbergi) to $1.98 \mathrm{Ma}$ (Dinofelis cf.

1107 barlowi). At present, the biochronological significance of the Drimolen Main Quarry $D$. aff.

1108 piveteaui is complicated by an unreliable FAD and LAD, but may suggest some deposition after

11091.98 to potentially $1.89-1.6 \mathrm{Ma}$.

1110

1111 Discussion

1112

1113 This first description and analysis of the macromammalian fossil specimens from the Drimolen

1114 Main Quarry assemblage has documented remarkably high taxonomic diversity (9 Orders, 14

1115 Families) relative to sample size (NISP: 1390, MNI: 147). While deposits like Swartkrans

1116 Member 1 record a somewhat greater range of taxa (9 Orders, 17 Families), the number of non-

1117 hominin taxonomically identifiable specimens underlying this diversity is substantially higher

1118 (NISP: 4583, MNI: 103; Watson, 1993). Despite this diversity, the McIntosh evenness statistic

1119 for the DMQ is low (0.71) and one standard deviation below the mean (0.80; range 0.60-0.93;

1120 s.d. 0.09) for South African early-mid Pleistocene localities (Table 6) and close to the value of

1121 the Haasgat HGD ex situ assemblage (0.72; Adams, 2012a). This low value reflects the high

1122 proportion of Papio hamadryas robinsoni individuals relative to all other taxa recovered from 
1123 the DMQ deposits. With the inclusion of Cercopithecoides williamsi and indeterminate

1124 specimens, 38.4\% of the DMQ assemblage come from the Family Cercopithecidae; equal to the

1125 proportion (38.4\%) of the second largest taxonomic group, the Family Bovidae. In this respect,

1126 DMQ is also similar to Haasgat HGD where non-human primates make up 35.1\% and bovids

1127 make up 40.9\% of the assemblage (Adams, 2012a); although we would reinforce that we are

1128 only considering the non-hominin components of the DMQ assemblage in comparison to the

1129 Haasgat HGD assemblage that lacks hominin remains.

1130

1131 The composition of the Drimolen Main Quarry bovid assemblage is not taxonomically unique

1132 relative to other penecontemporaneous South African fossil assemblages, but the numerical

1133 dominance of Antidorcas recki relative to other taxa is somewhat unusual (NISP: 25, MNI: 16,

$113428.6 \%$ total bovid assemblage). The only other sites with a similar sample size of $A$. recki are

1135 Cooper's D (MNI: 12; de Ruiter et al., 2009) and Kromdraai A (NISP: 44, MNI: 13; Brain,

1136 1981). In contrast to the DMQ assemblage, both have a far more substantial representation of

1137 alcelaphins (Cooper's D: MNI: 46; Kromdraai A: NISP: 220, MNI: 51) and A. recki only

1138 represents $12.0 \%$ (Cooper's D) and $11.5 \%$ (Kromdraai A) of the total bovid assemblage. What

1139 stands in rather strong contrast to the typical element-wise representation of bovid elements is

1140 the high frequency of horn cores in the DMQ assemblage (see Brain, 1981; Watson, 1993;

1141 Pickering, 1999), particularly in the case of $A$. recki, where very few teeth have been recovered

1142 alongside a substantial number of horn cores. Interpreting the origin and significance of this

1143 pattern of element preservation in the bovid sample compared to other palaeokarstic deposits is

1144 beyond the scope of the present paper, but will potentially be informative on the taphonomic

1145 processes underlying the Drimolen Main Quarry deposit formation. 
1147 The only other substantially represented taxonomic group in the DMQ assemblage is the Order

1148 Carnivora, which comprises $12.9 \%$ of the faunal assemblage and is biased towards the Family

1149 Felidae (57.9\% of the Carnivora and $7.5 \%$ of the overall faunal assemblage). This positions the

1150 DMQ assemblage as particularly carnivore-rich, with only Kromdraai B (15.8\%), Swartkrans

1151 Member 3 (16.9\%) and the Sterkfontein Member 5 deposits (West: 30.7\%; Olduwan Infill:

1152 13.6\%; STW 53 Breccia: 13.3\%) having higher proportions of carnivores amongst the

1153 penecontemporaneous South African palaeokarstic assemblages. The proportion of carnivores in

1154 the DMQ assemblage is also substantially less than the recently described Drimolen Makondo

1155 deposits (25.0\%; Rovinsky et al., 2015; Herries et al., in review), although the limited faunal

1156 sampling of the Makondo to-date (like other provisionally described faunal assemblages such as

1157 Motsetse [Berger and Lacruz, 2003], Hoogland [Adams et al., 2010], Malapa [Dirks et al., 2010;

1158 Kuhn et al., 2012]) necessitates further sampling to ensure these proportions are not artefacts of

1159 sample size. The co-occurrence of large predatory felids (with minimally three subfamilies and

1160 five genera represented in the deposit) - for example, Panthera, Dinofelis and Megantereon - is

1161 not uncommon in South African early Pleistocene deposits (Brain, 1981; Werdelin \& Peigné,

1162 2010). What is unusual is the potential sympatric occurrence of two species of Dinofelis recorded

1163 by the DMQ Dinofelis cf. barlowi and Dinofelis aff. piveteaui, specimens. While it has been

1164 noted that temporal overlap of two Dinofelis species may have been relatively common, at least

1165 in East Africa (e.g., Lewis and Werdelin, 2007), this current study would represent the first

1166 strong evidence of such contemporaneous overlap within a single deposit (Werdelin and Lewis,

1167 2001, 2013; Werdelin and Peigné, 2010). 
1169 The Drimolen Main Quarry faunal assemblage is also unique relative to most

1170 penecontemporaneous South African karstic deposits in the low representation of porcupine

1171 (Family Hystricidae) and hyrax (Family Procaviidae) remains in the deposits. These two families

1172 only comprise $2.7 \%$ of the total DMQ faunal assemblage, which falls below even the low

1173 proportions of these taxa at Sterkfontein Member 4 (4.2\%; Brain, 1981) and Kromdraai A (9.0\%;

1174 Brain, 1981), and strongly contrasts the representation of these families in the Swartkrans

1175 Member 1 (21.4\%; Watson, 1993) and Haasgat HGD (19.5\%; Adams, 2012a) faunal

1176 assemblages. There are a number of geologic (e.g., entrance morphology, deposit time-

1177 averaging), ecologic (e.g., immediate habitat and resource distribution) and/or taphonomic

1178 factors (e.g., pre-, peri- and postdepositional) that could underlie this low representation of these

1179 karst-utilising taxa that will require further analysis to assess.

1180

1181 In sum, this comprehensive accounting of the Drimolen Main Quarry faunal assemblage allows

1182 us to provide some initial comments on the palaeohabitats of the Drimolen region during

1183 depositon; although we note that a more comprehensive palaeoecological interpretation and

1184 analysis integrating stable isotopic results from the assemblage will be forthcoming. The overall

1185 vegetative communities and landscape ecology suggested by the taxon presence and abundance

1186 recovered from the DMQ deposits is largely consistent with the mixed, open-to-closed

1187 palaeohabitats that have been reconstructed for the other regional, penecontemporaneous South

1188 African palaeokarst deposits (Vrba, 1976, 1995; Brain, 1981; Benefit and McCrossin, 1990;

1189 McKee, 1991; Rayner, Moon \& Masters, 1993; Brain, 1995; Schmid, 2002; Elton, 2007; see also

1190 summaries in Reed, 1996; Kuman and Clarke, 2000; Adams, 2006). In part this reflects the broad

1191 habitat types that most of the specifically identifiable taxa from the DMQ deposits can occupy. 
1192 Both previously attributed primate taxa are larger-bodied and terrestrial (Papio hamadryas

1193 robinsoni, Cercopithecoides williamsi) and may have been sympatric, niche-partitioned primates

1194 adapted to the progressively more open habitats of the early Pleistocene (Elton, 2007; Jablonski

1195 and Frost, 2010). However, the composition and resource availability of these more open

1196 habitats, and how they contrast with earlier palaeoecosystems that supported cercopithecoids like

1197 Parapapio (that disappear from the record in the early Pleistocene), remains unresolved. Even

1198 the more unusual species recovered from the Drimolen Main Quarry deposits (indeterminate

1199 elephant, giraffe, and aardvark [Orycteropus cf. afer]) can unfortunately provide few constraints

1200 on the palaeohabitat types, distribution or proportions near the site. Neither the elephant or

1201 giraffe individual specimens could be confidently attributed below the level of Family, and

1202 extant aardvark populations occupy highly variable habitats across Africa with the only

1203 limitation being access to social insects (Kingdon and Hoffman, 2013a).

1204

1205 The dominance of Antidorcas recki in the bovid sample does not provide any specific evidence

1206 for reconstructing the overall vegetative community structure around Drimolen without further

1207 isotopic analysis. Although prior analyses of Sterkfontein and Swartkrans specimens have

1208 reconstructed the diet of this antilopin as a browser (Lee-Thorp and van der Merwe, 1993; Lee-

1209 Thorp, van der Merwe \& Brain, 1994; van der Merwe et al., 2003), a single specimen from

1210 Gondolin was interpreted as a mixed feeder (Adams, 2012a) and sampled individuals from

1211 Olduvai have documented greater dietary flexibility and an increase in graze in the species

1212 through the Bed I deposits associating them more with bushland to grassland palaeohabitats

1213 (Plummer et al., 2009). The only bovid taxa recovered from DMQ with specific habitat

1214 requirements are the mountain reedbuck (Redunca $\mathrm{cf}$. fulvorufula) and klipspringer (Oreotragus 
1215 sp.). Extant mountain reedbuck graze primarily in montane grasslands on rocky, hilly and/or

1216 broken terrain (Irby, 1976; Kingdon and Hoffman, 2013b); klipspringer exhibit a suite of

1217 musculoskeletal, physiological and behavioural adaptations to browsing on pair-defended rock

1218 outcrops (Norton, 1980; Kingdon and Hoffman, 2013b). The presence of some uplifted

1219 topography and/or local kopjes with montane grasses and browse near Drimolen during the

1220 formation of the Main Quarry assemblage is further reinforced by the recovery of hyrax

1221 (Procavia sp.) and rock hare (Pronolagus sp.) (Kingdon et al., 2013; Happold, 2013).

1222

1223 The extinct DMQ large carnivores are similarly reconstructed as adapted for hunting within a

1224 range of open and closed palaeohabitats. Both Dinofelis and Megantereon have been

1225 reconstructed as ambush predators preferring a closed-mixed habitat (Marean, 1989; Lewis,

1226 1995a, b, 1997; Palmqvist et al., 2003; Christiansen and Adolfssen, 2007; Palmqvist et al., 2008).

1227 In its postcranial anatomy, the smaller-bodied Megantereon is reminiscent of the extant jaguar

1228 (Panthera onca), with relatively short, heavily muscled, and powerful limbs (Lewis, 1995b,

1229 1997; Christiansen and Adolfssen, 2007). Isotopic analyses of European Megantereon support

1230 the preference for a closed-mixed habitat, suggesting that the genus predated on browsers and

1231 mixed-feeders (Palmqvist et al., 2003, 2008). Dinofelis has been shown to have had greater

1232 flexibility in the forelimb than seen in the other African machairodonts (i.e. Homotherium,

1233 Megantereon; Lewis, 1995a, b, 1997) and a trend in the larger-bodied species toward a more

1234 Panthera-like cranial and postcranial anatomy, suggesting that although it seems to have been an

1235 ambush grappler much like Megantereon it may have been able to exploit a larger range of

1236 habitats than the other African sabertooth genera (Lewis, 1997; Lewis and Werdelin, 2007).

1237 Although postcranial remains of African Lycyaenops and Chasmaporthetes species are extremely 
1238 rare (see Rovinsky et al., 2015), cursorial adaptations within the hunting-hyaena lineage supports

1239 more open habitats in the region, in contrast to the felids (Khomenko, 1932; Galiano and Frailey,

1240 1977; Berta, 1981; Tseng, Li and Wang, 2013). Amongst the extant carnivores identified by

1241 O'Regan and Menter (2009) modern populations of Cape fox (Vulpes chama), yellow mongoose

1242 (cf. Cynictis penicillata), and meerkat (aff. Suricata suricatta) typically occupy open, semi-arid

1243 to arid ecosystems (Kingdon and Hoffmann, 2013a). Interestingly, the extensive burrowing

1244 behaviour of meerkat and yellow mongoose also imply the presence of deep soils, with the latter

1245 avoiding rocky and hard soil regions for burrow construction (Kingdon and Hoffman, 2013a).

\section{Conclusions}

1249 This first description of the non-primate faunas of the Drimolen Main Quarry provides an insight

1250 into the macromammalian community structure of a previously undescribed part of the Cradle of

1251 Humankind during the Early Pleistocene of South Africa. The fauna recovered suggests a

1252 community of great taxonomic breadth. Amongst the sampled Order Carnivora in particular

1253 there is a surprising amount of diversity, with a minimum of four large species of felid present

1254 alongside at least four hyaenid species, including the first strong evidence of two species of

1255 Dinofelis recovered from a single deposit (but see Werdelin and Lewis, 2013). Although there is

1256 a large amount of taxonomic diversity amongst the fauna, non-hominin primates comprise a

1257 significant percentage of the assemblage - a disparity that will only increase when the substantial

1258 Drimolen hominin sample is included in the overall faunal picture. As this publication provides

1259 the primary description of the recovered DMQ faunas, further analyses will need to be

1260 undertaken to understand the idiosyncrasies of the site, ranging from the taphonomic processes 
1261 shaping the assemblage (particularly the large number of bovid horn cores and concomitant

1262 paucity of dental and postcranial remains) to a more integrated palaeoecological analysis of the

1263 Main Quarry.

1264

\section{Acknowledgements}

1266

1267 The Drimolen Main Quarry faunas described here have been developed over the course of over

1268 two decades, and we would like to acknowledge the efforts of past and ongoing excavation

1269 assistants, field school students and preparators in developing this material; specifically

1270 Stephanie E. Baker for her ongoing curatorial and site management work. We would also like to

1271 thank Bernhard Zipfel (Evolutionary Studies Institute, University of the Witwatersrand) for

1272 facilitating access to the DMQ fossil specimens, as well as Shaw Badenhorst (Archaeozoology

1273 and Large Mammals Collections), Stephany Potze and Lazarus Kgasi (Plio-Pleistocene Section)

1274 of the Ditsong National Museum of Natural History for facilitating access to modern and fossil

1275 comparative collections used in this research. Rhiannon Stammers assisted with the Dino-Lite

1276 Edge AM4815ZTZ microscope used to evaluate several of the DN specimens described here.

1278 References

1279

1280 Adams JW. 2006. Taphonomy and paleoecology of the Gondolin Plio-Pleistocene cave site,

1281 South Africa. D. Phil. Thesis, Washington University in St. Louis. 
1282 Adams JW. 2012a. Craniodental and postcranial remains of the extinct porcupine Hystrix

1283 makapanensis Greenwood, 1958 (Rodentia: Hystricidae) from Gondolin, South Africa Annals of

1284 the Ditsong National Museum of Natural History 2:7-17.

1285 Adams JW. 2012b. A revised listing of fossil mammals from the Haasgat cave system ex situ

1286 deposits (HGD), South Africa. Palaeontologia Electronica 15:88.

1287 Adams JW, and Conroy GC. 2005. Plio-Pleistocene faunal remains from the Gondolin GD 2 in

1288 situ assemblage, North West Province, South Africa. In: Lieberman D, Smith RJ, and Kelley J,

1289 eds. Interpreting the past: essays on human, primate and mammal evolution in honor of David

1290 Pillbeam. Boston: Brill Academic Publishers, 243-261.

1291 Adams JW, Herries AIR, Hemingway J, Kegley ADT, Kgasi L, Hopley P, Reade H, Potze S, and

1292 Thackeray JF. 2010. Initial fossil discoveries from Hoogland, a new Pliocene primate-bearing

1293 karstic system in Gauteng Province, South Africa. Journal of Human Evolution 59:685-691.

1294 Benefit B, and McCrossin M. 1990. Diet, species diversity, and distribution of African fossil

1295 baboons. Kroeber Anthropological Society Papers 71:79-93.

1296 Berger LR, and Lacruz R. 2003. Preliminary report on the first excavations at the new fossil site

1297 of Motsetse, Gauteng, South Africa. South African Journal of Science 99:279-282.

1298 Berta A. 1981. The Plio-Pleistocene hyaena Chasmaporthees ossifragus from Florida. Journal of

1299 Vertebrate Paleontology 1:341-356.

1300 Biknevicius AR, Van Valkenburgh B, Walker J. 1996. Incisor size and shape: Implications for

1301 feeding behaviors in saber-toothed "cats". Journal of Vertebrate Paleontology 16:510-521.

1302 Bishop L. 1994. Pigs and ancestors: hominids, suids and environments during the Plio-

1303 Pleistocene of east Afric. D. Phil. Thesis, Yale University. 
1304 Brain C. 1980. Some criteria for the recognition of bone collecting agencies in African caves. In:

1305 Behrensmeyer AK, and Hill A, eds. Fossils in the making. Chicago: University of Chicago Press, $1306 \quad 107-130$.

1307 Brain C. 1995. The influence of climatic changes on the completeness of the early hominid

1308 record in Southern African caves, with particular reference to Swartkrans. In: Vrba E, Denton G,

1309 Partridge T, and Burckle L, eds. Paleoclimate and evolution with emphasis on human origins.

1310 New Haven: Yale University Press, 451-458.

1311 Braun D, Levin N, Stynder D, Herries AIR, Archer W, Forrest F, Roberts D, Bishop L,

1312 Matthews T, Lehmann S, Pickering R, and Fitzsimmons K. 2013. Mid-Pleistocene hominin

1313 occupation at Elandsfontein, Western Cape, South Africa. Quaternary Science Reviews 82:145-

1314166.

1315 Broom R. 1948. Some South African Pliocene and Pleistocene mammals. Annals of the

1316 Transvaal Museum 21:1-38.

1317 Churcher C. 1956. The fossil Hyracoidea of the Transvaal and Taungs deposits. Annals of the

1318 Transvaal Museum 22:477-501.

1319 Churcher C, and Watson V. 1993. Additional fossil Equidae from Swartkrans. In: Brain C, ed.

1320 Swartkrans: a cave's chronicle of early man. Pretoria: Transvaal Museum, 137-150.

1321 Christiansen P, Adolfssen JS. 2007. Osteology and ecology of Megantereon cultridens SE311

1322 (Mammalia; Felidae; Machairodontinae), a sabrecat from the Late Pliocene - Early Pleistocene

1323 of Senéze, France. Zoological Journal of the Linnean Society 151:833-884.

1324 Cooke H. 1974. The fossil mammals of Cornelia, O.F.S., South Africa. Memoirs of the National 1325 Museum Bloemfontein 7:63-84. 
1326 Cooke H. 1996. Sexual dimorphism in Antidorcas recki from Bolt's Farm, South Africa, in the

1327 University of California collections. In: Stewart K, and Seymour K, eds. Palaeoecology and

1328 palaeoenvironments of the late Cenozoic mammals. Toronto: University of Toronto Press, 5371329553.

1330 de Ruiter DJ, Pickering R, Steininger CM, Kramers JD, Hancox PJ, Churchill SE, Berger LR, 1331 and Backwell L. 2016. New Australopithecus robustus fossils and associated U-Pb dates from 1332 Cooper's Cave (Gauteng, South Africa). Journal of Human Evolution 56:497-513.

1333 Dirks P, Kibii J, Kuhn B, Steininger C, Churchill S, Kramers J, Pickering R, Farber D, Merlaux 1334 A, Herries AIR, King G, and Berger LR. 2010. Geological setting and age of Australopithecus 1335 sediba from southern Africa. Science 328:205-208.

1336 Elton S. 2007. Environmental correlates of the cercopithecoid radiations. Folia Primatologia $1337 \quad 78: 344-364$.

1338 Ewer R. 1955a. The fossil carnivores of the Transvaal caves: Machairodontinae. Proceedings of 1339 the Zooogical Society of London 125:587-615.

1340 Ewer R. 1955b. The fossil carnivores of the Transvaal caves: the Lycyaenas of Sterkfontein and

1341 Swartkrans, together with some general considerations of the Transvaal fossil hyaenids.

1342 Proceedings of the Zooogical Society of London 124:839-857.

1343 Galiano H, and Frailey D. 1977. Chasmaporthetes kani: New species from China, with remarks 1344 on phylogenetic relationships of genera within the Hyaenidae (Mammalia, Carnivora). American 1345 Museum Novitates 2632:1-16.

1346 Gallagher A, and Menter CG. 2011. DNH 109: a fragmentary hominin near-proximal ulna from

1347 Drimolen, South Africa. South African Journal of Science 107:1-4. 
1348 Gentry A. 1966. Fossil Antilopini of East Africa. Bulletin of the British Museum of Natural

1349 History (Geology) 12:4-125.

1350 Gentry A. 2010. Bovidae. In: Werdelin L, and Sanders W, eds. Cenozoic mammals of Africa.

1351 Berkeley: University of California Press, 741-796.

1352 Gentry A, and Gentry A. 1978. Fossil Bovidae (Mammalia) of Olduvai Gorge, Tanzania, Part I.

1353 Bulletin of the British Museum of Natural History (Geology) 29:289-446.

1354 Geraads D, Raynal J, and Eisenmann V. 2004. The earliest human occupation of North Africa: a

1355 reply to Sahnouni et al. (2002). Journal of Human Evolution 46:751-761.

1356 Gilbert C, Steininger C, Kibii J, and Berger LR. 2015. Papio cranium from the hominin-bearing

1357 site of Malapa: implications for the evolution of modern baboon cranial morphology and South

1358 African Plio-Pleistocene biochronology. PLoS One 10:e0133361.

1359 Gilbert C, Frost S, and Delson E. 2016. Reassessment of Olduvai Bed I cercopithecoids: A new

1360 biochronological and biogeographical link to the South African fossil record. Journal of Human

1361 Evolution 92:50-59.

1362 Gommery D, Senut B, and Keyser AW. 2002. A fragmentary pelvis of Paranthropus robustus of

1363 the Plio-Pleistocene site of Drimolen (Republic of South Africa). Geobios 35:265-281.

1364 Happold D. 2013. Volume III: Rodents, hares and rabbits. Mammals of Africa. London:

1365 Bloomsbury. p 784.

1366 Harris J. 1976. Pleistocene Giraffidae (Mammalia, Artiodactyla) from East Rudolf, Kenya. In:

1367 Savage R, and Coryndon S, eds. Fossil vertebrates of Africa. New York: Academic Press, 283-

1368332.

1369 Harris J. 1991. Family Giraffidae. In: Harris J, ed. The fossil ungulates: geology, fossil

1370 artiodactyls, and palaeonenvironments. Oxford: Clarendon Press, 93-138. 
1371 Herries AIR, Curnoe D, and Adams JW. 2009. A multi-disciplinary seriation of early Homo and

1372 Paranthropus bearing palaeocaves in southern Africa. Quaternary International 202:14-28.

1373 Herries AIR, and Shaw J. 2011. Palaeomagnetic analysis of the Sterkfontein palaeocave

1374 deposits: implications for the age of the hominin fossils and stone tool industries. Journal of

1375 Human Evolution 60:523-539.

1376 Herries AIR, and Adams JW. 2013. Clarifying the context, dating and age range of the Gondolin

1377 hominins and Paranthropus in South Africa. Journal of Human Evolution 65: 676-681.

1378 Herries AIR, Pickering R, Adams JW, Curnoe D, Warr G, Latham A, and Shaw J. 2013. A

1379 multi-disciplinary perspective on the age of Australopithecus in southern Africa. In: Leakey R,

1380 Fleagle J, and Reed K, eds. The Paleobiology of Australopithecus. Vertebrate Paleobiology and

1381 Paleoanthropology Series, Springer Science and Business Media, 21-40.

1382 Herries AIR, Boschian G, Pickering R, Rovinsky D, Adams JW, Armstrong B, Baker S,

1383 Blackwood A, Caruana M, Kajewski PP, Murszewski A, and Menter C. In review. Drimolen

1384 Makondo: a new Plio-Pleistocene fossil bearing palaeocave fill from the Drimolen hominin site,

1385 Gauteng, South Africa. Quaternary Research.

1386 Irby L. 1976. The ecology of mountain reedbuck in southern and eastern Africa. D. Phil. Thesis,

1387 Texas A\&M University.

1388 Jablonski N, and Frost S. 2010. Cercopithecoidea. In: Werdelin L, and Sanders W, eds. Cenozoic

1389 mammals of Africa. Berkeley: University of California Press, 393-428.

1390 Keyser AW, Menter CG, Moggi-Cecchi J, Pickering TR, and Berger LR. 2000. Drimolen: A new

1391 hominid-bearing site in Gauteng, South Africa. South African Journal of Science 96:193-197.

1392 Khomenko IP. 1932. Hyaena borissiaki n. sp. iz russil'onskoj fauny Bessarabii. Travaux de

1393 l'Institut Paléozoologique de l'Academie des Sciences de 1’U.R.S.S. 1:81-134. 
1394 Kingdon J, and Hoffmann M. 2013. Volume V: Carnivores, pangolins, equids and rhinoceroses.

1395 Mammals of Africa. London: Bloomsbury. p 560.

1396 Kuhn B, Werdelin L, Hartstone-Rose A, Lacruz R, and Berger LR. 2012. Carnivoran remains

1397 from the Malapa hominin site, South Africa. PLoS One 6:e26940.

1398 Kuman K, and Clarke RJ. 2000. Stratigraphy, artefact industries and hominid associations for

1399 Sterkfontein, Member 5. Journal of Human Evolution 38:827-847.

1400 Lacruz R, Brink J, Hancox P, Skinner A, Herries AIR, Schmid P, and Berger LR. 2002.

1401 Palaeontology and geological context of a middle Pleistocene faunal assemblage from the

1402 Gladysvale cave, South Africa. Palaeontologia africana 38:99-114.

1403 Lacruz R, Turner A, and Berger LR. 2006. New Dinofelis (Carnivora: Machairodontinae)

1404 remains from Sterkfontein Valley sites and a taxonomic revision of the genus in southern Africa.

1405 Annals of the Transvaal Museum 43:89-106.

1406 Leakey M, and Harris J. 1987. Laetoli: a Pliocene site in Northern Tanzania. Oxford: Clarendon 1407 Press. p 545.

1408 Lee-Thorp J, and van der Merwe N. 1993. Stable carbon isotope studies of Swartkrans fossils.

1409 In: Brain C, ed. Swartkrans: a cave's chronicles of early man. Pretoria: Transvaal Museum.

1410 Lee-Thorp J, van der Merwe N, and Brain C. 1994. Diet of Australopithecus robustus at

1411 Swartkrans from stable carbon isotope analysis. Journal of Human Evolution 27:361-372.

1412 Lehmann T. 2004. Fossil aardvark (Orycteropus) from Swarkrans Cave, South Africa. South

1413 African Journal of Science 100:311-314.

1414 Lewis M. 1995a. Plio-Pleistocene carnivoran guilds: implications for hominid paleoecology. D.

1415 Phil. Thesis, State University of New York at Stony Brook. 
1416 Lewis ME. 1995b. Functional morphology of the sabertoothed felid Megantereon from

1417 Kromdraai, South Africa [abstract]. Journal of Vertebrate Paleontology 15:40A.

1418 Lewis M. 1997. Carnivoran paleoguilds of Africa: implications for hominid food procurement

1419 strategies. Journal of Human Evolution 32:257-288.

1420 Lewis M, and Werdelin L. 2007. Patterns of change in the Plio-Pleistocene carnivorans of

1421 eastern Africa: implications for hominin evolution. In: Bobe R, Alemseged Z, and Behrensmeyer

1422 AK, eds. Hominin environments in the east African Pliocene: an assessment of the faunal

1423 evidence. Berlin: Springer, 77-105.

1424 Lockwood C, Menter CG, Moggi-Cecchi J, and Keyser AW. 2007. Extended male growth in a

1425 fossil hominin species. Science 318:1443-1446.

1426 Marean CW. 1989. Sabertooth cats and their relevance for early hominid diet and evolution.

1427 Journal of Human Evolution 18:559-582.

1428 McDougall I, Brown F, Vasconcelos P, Cohen B, Thiede D, and Buchanan M. 2011. New single

1429 crystal ${ }^{40} \mathrm{Ar} /{ }^{39} \mathrm{Ar}$ ages improve time scale for deposition of the Omo Group, Omo-Turkana Basin,

1430 East Africa. Journal of the Geological Society 169:213-226.

1431 McIntosh R. 1967. An index of diversity and the relation of certain aspects of diversity. Ecology

1432 48:392-404.

1433 McKee J. 1991. Palaeo-ecology of the Sterkfontein hominids: a review and synthesis.

1434 Palaeontologia africana 28:41-51.

1435 Moggi-Cecchi J, Menter CG, Boccone S, and Keyser AW. 2010. Early hominin dental remains

1436 from the Plio-Pleistocene site of Drimolen, South Africa. Journal of Human Evolution 58:374-

1437405. 
1438 Nieuwoudt C. 2014. A taphonmic study of the Cercopithecidae sample from Drimolen, South

1439 Africa. Honours Thesis, University of Johannesburg.

1440 O'Regan H, and Menter CG. 2009. Carnivora from the Plio-Pleistocene hominin site of

1441 Drimolen, Gauteng, South Africa. Geobios 42:329-350.

1442 Palmqvist P, Groeke D, Arribas A, and Farina R. 2003. Paleoecological reconstruction of a lower

1443 Pleistocene large mammal community using biogeochemical $\left(\delta^{13} \mathrm{C}, \delta^{15} \mathrm{~N}, \delta^{18} \mathrm{O}\right.$, Sr:Zn) and

1444 ecomorphological approaches. Paleobiology 29:205-229.

1445 Palmqvist P, Perez-Carlos J, Janis C, Figueirido B, Torregrosa V, and Grocke D. 2008.

1446 Biogeochemical and ecomorphological inferences on prey selection and resource partitioning

1447 among mammalian carnivores in an early Pleistocene community. Palaois 23:724-737.

1448 Palmqvist P, Torregrosa V, Perez-Claros J, Martinez-Navarro B, and Turner A. 2007. A re-

1449 evaluation of the diversity of "Megantereon" (Mammalia, Carnivora, Machairodontinae) and the

1450 problem of species identification in extinct carnivores. Journal of Vertebrate Paleontology

$1451 \quad 27: 160-175$.

1452 Pickering TR. 1999. Taphonomic interpretations of the Sterkfontein early hominid site (Gauteng,

1453 South Africa) reconsidered in light of recent evidence. D. Phil. Thesis, University of Wisconsin.

1454 Pickering R, Kramers JD, Hancox PJ, de Ruiter, DJ, and Woodhead JD. 2011. Contemporary

1455 flowstone development links early hominin bearing cave deposits in South Africa. Earth and

1456 Planetary Science Letters 306: 23-32.

1457 Pickering R, Dirks P, Jinnah Z, de Ruiter DJ, Churchill SE, Herries AIR, Woodhead J, Hellstrom

1458 J, and Berger LR. 2011. Australopithecus sediba at 1.977 Ma and implications for the origins of

1459 the genus Homo. Science. 333: 1421-1423. 
1460 Plummer T, Ditchfield P, Bishop L, Kingston J, Ferraro J, Braun D, Hertel F, and Potts R. 2009.

1461 Oldest evidence of toolmaking hominins in a grassland-dominated ecosystem. PLoS One

1462 4:e7199.

1463 Rayner R, Moon B, and Masters J. 1993. The Makapansgat australopithcine environment.

1464 Journal of Human Evolution 24:219-231.

1465 Reed KE. 1996. The paleoecology of Makapansgat and other African Plio-Pleistocene hominid

1466 localities, D. Phil Thesis, State University of New York at Stony Brook.

1467 Robinson C. 2011. Giraffidae. In: Harrison T, ed. Paleontology and geology of Laetoli: human

1468 evolution in context. New York: Springer, 339-362.

1469 Rovinsky DS, Herries AIR, Menter CG, Adams JW. 2015. First description of in situ primate

1470 and faunal remains from the Plio-Pleistocene Drimolen Makondo palaeocave infill, Gauteng,

1471 South Africa. Palaeontologia Electronica 18:1-21.

1472 Schmid P. 2002. The Gladysvale project. Evolutionary Anthropology 11:45-48.

1473 Schwartz G. 1997. Re-evaluation of the Plio-Pleistocene hyraxes (Mammalia: Procaviidae) from

1474 South Africa. Neues Jahrbuch fur Geologie und Palaeontologie, Abhandlungen 206:365-383.

1475 Tamrat E, Thouveny N, Taieb M, and Opdyke N. 1995. Revised magnetostratigraphy of the Plio-

1476 Pleistocene sedimentary sequence of the Olduvai Formation (Tanzania). Palaeogeography,

1477 Palaeoclimatology, Palaeoecology 114:273-283.

1478 Tseng Z, Li Q, and Wang X. 2013. A new cursorial hyena from Tibet, and analysis of the

1479 biostratigraphy, paleozoogeography, and dental morphology of Chasmaporthetes (Mammalia,

1480 Carnivora). Journal of Vertebrate Paleontology 33:1457-1471. 
1481 Turner A. 1984. The interpretation of variation in fossil specimens of spotted hyaena (Crocuta

1482 crocuta Erxleben, 1777) from Sterkfontein Valley Sites (Mammalia: Carnivora). Annals of the

1483 Transvaal Museum 33:399-418.

1484 Turner A. 1986. Miscellaneous carnivore remains from Plio-Pleistocene deposits in the

1485 Sterkfontein Valley (Mammalia: Carnivora). Annals of the Transvaal Museum 34:203-226.

1486 Turner A. 1987a. Megantereon cultridens (Cuvier)(Mammalia, Felidae, Machairodontinae) from

1487 Plio-Pleistocene deposits in Africa and Eurasia, with comments on dispersal and possibility of a

1488 New World origin. Journal of Paleontology 61:1256-1268.

1489 Turner A. 1987b. New fossil carnivore remains from the Sterkfontein hominid site (Mammalia:

1490 Carnivora). Annals of the Transvaal Museum 34:319-347.

1491 Turner A. 1990. The evolution of the guild of larger terrestrial carnivores during the Plio-

1492 Pleistocene in Africa. Geobios 23:349-368.

1493 Turner A. 1993. New fossil carnivore remains from Swartkrans. In: Brain C, ed. Swartkrans: $a$

1494 cave's chronicle of early man. Pretoria: Transvaal Museum, 151-166.

1495 Turner A. 1997. Further remains of Carnivora (Mammalia) from the Sterkfontein hominid site.

1496 Palaeontologia africana 34:115-126.

1497 van der Merwe N, Thackeray JF, Lee-Thorp J, and Luyt J. 2003. The carbon isotope ecology and

1498 diet of Australopithecus africanus at Sterkfontein, South Africa. Journal of Human Evolution

1499 44:581-597.

1500 Vrba E. 1976. The fossil Bovidae of Sterkfontein, Swartkrans and Kromdraai. Pretoria: Transvaal 1501 Museum. 
1502 Vrba E. 1995. The fossil record of African antelopes (Mammalia, Bovidae) in relation to human

1503 evolution and paleoclimate. In: Vrba E, Denton G, Partridge T, and Burckle L, eds. Paleoclimate

1504 and evolution with emphasis on human origins. New Haven: Yale University Press, 385-425.

1505 Vrba E. 1997. New fossils of Alcelaphini and Caprinae (Bovidae: Mammalia) from Awash,

1506 Ethiopia, and phylogenetic analysis of Alcelaphini. Palaeontologia africana 34:127-198.

1507 Watson V. 1993. Composition of the Swartkrans bone accumulations, in terms of skeletal parts

1508 and animals represented. In: Brain C, ed. Swartkrans: a cave's chronicle of early man. Pretoria:

1509 Transvaal Museum, 35-74.

1510 Werdelin L, Lewis ME. 2001. A revision of the genus Dinofelis (Mammalia, Felidae).

1511 Zoological Journal of the Linnean Society 132:147-258.

1512 Werdelin L, Lewis ME. 2005. Plio-Pleistocene Carnivora of eastern Africa: species richness and

1513 turnover patterns. Zoological Journal of the Linnean Society 144:121-144.

1514 Winkler A, and Avery D. 2010. Lagomorpha. In: Werdelin L, and Sanders W, eds. Cenozoic

1515 mammals of Africa. Berkeley: University of California Press, 305-318.

1516 Werdelin L, and Dehghani R. 2011. Carnivora. In: Harrison T, ed. Paleontology and geology of

1517 Laetoli: human evolution in context. New York: Springer, 189-232.

1518 Werdelin L, Lewis ME. 2013. Koobi Fora Research Project Volume 7: The Carnivora. San

1519 Francisco: California Academy of Sciences.

1520 Werdelin L, and Peigne S. 2010. Carnivora. In: Werdelin L, and Sanders W, eds. Cenozoic

1521 mammals of Africa. Berkeley: University of California Press, 603-658. 


\section{Table $\mathbf{1}$ (on next page)}

List of macromammalian species from the Drimolen Main Quarry deposits 
Table 1. List of macromammalian species from the Drimolen Main Quarry deposits

\begin{tabular}{|c|c|c|}
\hline \multirow{2}{*}{\multicolumn{3}{|c|}{$\begin{array}{l}\text { Taxon } \\
\text { Order Primates }^{1}\end{array}$}} \\
\hline & & \\
\hline \multicolumn{3}{|l|}{ Family Cercopithecidae } \\
\hline \multicolumn{3}{|l|}{ Subfamily Colobinae } \\
\hline Cercopithecoides williamsi & 22 & 8 \\
\hline \multicolumn{3}{|l|}{ Tribe Papionini } \\
\hline Papio hamadryas robinsoni & 260 & 45 \\
\hline Cercopithecidae indet. & 272 & 4 \\
\hline \multicolumn{3}{|l|}{ Order Carnivora $^{2}$} \\
\hline \multicolumn{3}{|l|}{ Family Canidae } \\
\hline Vulpes chama & 1 & 1 \\
\hline cf. Vulpes chama & 1 & - \\
\hline Canidae indet. & 5 & 1 \\
\hline \multicolumn{3}{|l|}{ Family Felidae } \\
\hline \multicolumn{3}{|l|}{ Subfamily Machairodontinae } \\
\hline Dinofelis aff. piveteaui & 17 & 2 \\
\hline ?Dinofelis sp. & 1 & - \\
\hline Dinofelis cf. barlowi* & 1 & 1 \\
\hline Megantereon whitei* & 2 & 1 \\
\hline Machairodontinae indet. & 1 & 1 \\
\hline \multicolumn{3}{|l|}{ Subfamily Pantherinae } \\
\hline Panthera pardus & 5 & 1 \\
\hline cf. Panthera pardus & 3 & 1 \\
\hline Panthera sp. & 1 & - \\
\hline \multicolumn{3}{|l|}{ Subfamily Felinae } \\
\hline cf. Caracal caracal & 1 & 1 \\
\hline Felis silvestris lybica & 3 & 1 \\
\hline cf. Felis silvestris lybica & 4 & 2 \\
\hline Felidae indet.* & 31 & - \\
\hline \multicolumn{3}{|l|}{ Family Herpestidae } \\
\hline aff. Suricata suricatta & 1 & 1 \\
\hline cf. Cynictis penicillata & 3 & 1 \\
\hline \multicolumn{3}{|l|}{ Family Hyaenidae } \\
\hline Chasmaporthetes nitidula* & 1 & 1 \\
\hline Lycyaenops silberbergi* & 1 & 1 \\
\hline Hyaenidae indet.* & 7 & 2 \\
\hline Carnivora indet. & 15 & - \\
\hline \multicolumn{3}{|l|}{ Order Cetartiodactyla } \\
\hline \multicolumn{3}{|l|}{ Family Bovidae } \\
\hline \multicolumn{3}{|l|}{ Tribe Alcelaphini } \\
\hline Connochaetes sp. & 2 & 2 \\
\hline Damaliscus sp. & 2 & 2 \\
\hline
\end{tabular}


Megalotragus sp.

Indeterminate (Class II/III)

Indeterminate (Class III)

Tribe Antilopini

Antidorcas recki

Antidorcas cf. recki

Raphicerus sp.

Tribe Oreotragini

Oreotragus sp.

Tribe Reduncini

Redunca cf. fulvorufula

Tribe Tragelaphini

Tragelaphus sp.

Indeterminate

Bovidae indet.

Family Giraffidae

Giraffidae indet.

Family Suidae

Suidae indet.

Order Perissodactyla

Family Equidae

Equus quagga ssp.

Order Proboscidea

Family Elephantidae

Elephantidae indet.

Order Hyracoidea

Family Procaviidae

Procavia sp.

Order Lagomorpha

Family Leporidae

Pronolagus sp.

Leporidae indet.

Order Rodentia

Family Hystricidae

Hystrix sp.

Order Tubulidentata

Family Orycteropodidae
42

349

114

$25 \quad 16$

$26 \quad 2$

$1 \quad 1$

129

$3 \quad 3$

$11 \quad 6$

2

538

1

1

$1-1$

$3-1$

$5 \quad 3$

$\begin{array}{cc}1 & 1 \\ 36 & 5\end{array}$

$1-1$ 


\begin{tabular}{lcc} 
Orycteropus cf. afer & 1 & 1 \\
\hline Total & 1380 & 147
\end{tabular}

${ }^{1}$ Taxonomic attributions, specimen counts, and MNI values as reported by Nieuwoudt (2014).

${ }^{2}$ Taxonomic attributions, specimens counts, and MNI values as reported by O'Regan and Menter (2009) except where amended here (amended taxa and/or counts marked with an asterisk).

1 


\section{Table 2 (on next page)}

Measurements (in mm) of Drimolen Main Quarry Felidae gen. et sp. indet and comparative maxillary fourth premolars body. 
Table 2. Measurements (in mm) of Drimolen Main Quarry Felidae gen. et sp. indet and comparative maxillary fourth premolars

\begin{tabular}{|c|c|c|c|c|c|c|}
\hline Specimen & Deposit & MD & $\mathrm{BL}$ & Wpc & $\mathrm{PaL}$ & MtL \\
\hline \multicolumn{7}{|c|}{ Felidae gen. et sp. indet. } \\
\hline DN 4300 & Drimolen Main Quarry & 29.8 & 11.6 & 9.4 & 11.8 & 12.3 \\
\hline DN 5498 & Drimolen Main Quarry & $30.2 *$ & $11.6 *$ & 9.3 & $11.1 *$ & 11.9 \\
\hline \multicolumn{7}{|c|}{ Megantereon whitei } \\
\hline DN 976 & Drimolen Main Quarry & $23.4 *$ & $11.2 *$ & 9.6 & 10.0 & 10.6 \\
\hline KA 64 & Kromdraai A & 29.7 & $11.1 *$ & $9.7 *$ & 9.6 & 10.8 \\
\hline \multicolumn{7}{|c|}{ Dinofelis piveteaui and aff. piveteaui } \\
\hline DN 1012 & Drimolen Main Quarry & 36.5 & 13.9 & & 13.5 & 14.3 \\
\hline KA 61 & Kromdraai A & 41.0 & 13.0 & & & 17.8 \\
\hline MT $1986^{1}$ & Motsetse & 38.8 & 12.8 & & & 16.5 \\
\hline \multicolumn{7}{|c|}{ Dinofelis barlowi } \\
\hline BF 55-22 & Bolt's Farm Pit 23 & $37.0 *$ & 16.5 & & & 14.0 \\
\hline SF $5855^{1}$ & Sterkfontein Member 4 & 35.2 & 15.5 & & 13.0 & $13.7 *$ \\
\hline
\end{tabular}

*Minimum value given damage to measured region.

${ }^{1}$ Measurements of Motsetse and Sterkfontein Member 4 specimens derived from Lacruz et al. (2006). 


\section{Table 3(on next page)}

Regression equations and metrics for the Felidae canine shape groups in Figure 4. Maxillary canine MD length and $\mathrm{BL}$ width (in $\mathrm{mm}$ ), along with the canine compression ratio (BL/MD). 
Table 3. Regression equations and metrics for the Felidae canine shape groups in Figure 4. Maxillary canine MD length and BL width (in $\mathrm{mm}$ ), along with the canine compression ratio (BL/MD).

\begin{tabular}{|c|c|c|c|}
\hline Canine Morphology & \multicolumn{2}{|l|}{ Regression Equation } & $\mathrm{R}^{2}$ \\
\hline Conical-toothed & \multicolumn{2}{|c|}{$y=0.7533 x+1.2559$} & 0.9567 \\
\hline False Saber-toothed & \multicolumn{2}{|c|}{$y=0.7119 x-2.0968$} & 0.9096 \\
\hline Saber-toothed & \multicolumn{2}{|c|}{$y=0.495 x-0.01$} & 0.8754 \\
\hline & MD Length (mm) & BL Width (mm) & Compression Ratio \\
\hline Conical-toothed Felids & & & 0.83 \\
\hline Puma concolor $(\mathrm{n}=28)^{\mathrm{a}}$ & 12.9 & 11.7 & 0.91 \\
\hline Neofelis nebulosa $(\mathrm{n}=18)^{\mathrm{a}}$ & 11.5 & 8.2 & 0.72 \\
\hline Panthera uncia $(\mathrm{n}=12)^{\text {a }}$ & 11.9 & 11.1 & 0.93 \\
\hline Panthera tigris $(\mathrm{n}=28)^{\text {a }}$ & 24.3 & 19.7 & 0.81 \\
\hline Panthera onca $(\mathrm{n}=20)^{\text {a }}$ & 19.1 & 15.9 & 0.83 \\
\hline Panthera pardus $(\mathrm{n}=26)^{a}$ & 14.7 & 12.4 & 0.85 \\
\hline Panthera leo $(\mathrm{n}=17)^{\mathrm{a}}$ & 23.3 & 18.3 & 0.78 \\
\hline False Saber-toothed Felids & & & 0.61 \\
\hline Dinofelis petteri $(\mathrm{n}=2)^{\mathrm{b}}$ & 21.0 & 12.7 & 0.60 \\
\hline Dinofelis aronoki ${ }^{\mathrm{b}}$ & 20.4 & 12.8 & 0.63 \\
\hline Dinofelis barlowi $(\mathrm{n}=4)^{b}$ & 24.1 & 14.6 & 0.61 \\
\hline Dinofelis piveteaui & 20.5 & 12.2 & 0.59 \\
\hline Dinofelis cf. diastemata $(\mathrm{n}=2)^{b}$ & 20.2 & 11.9 & 0.59 \\
\hline Dinofelis cristata $(\mathrm{n}=2)^{\mathrm{b}}$ & 25.3 & 16.9 & 0.67 \\
\hline Dinofelis palaeoonca ${ }^{b}$ & 18.6 & 11.7 & 0.63 \\
\hline Dinofelis $\mathrm{sp}^{\mathrm{b}}$ & 24.8 & 15.1 & 0.61 \\
\hline DN 2791 & 23.2 & 14.1 & 0.61 \\
\hline Saber-toothed Felids & & & 0.51 \\
\hline Homotherium serum ${ }^{\text {a }}$ & 34.6 & 15.8 & 0.46 \\
\hline Megantereon cultridens $(\mathrm{n}=27)^{\mathrm{a}, \mathrm{c}}$ & 22.6 & 11.6 & 0.51 \\
\hline Megantereon whitei $(\mathrm{n}=8)^{\mathrm{c}}$ & 24.1 & 12.3 & 0.51 \\
\hline Smilodon fatalis ${ }^{c}$ & 44.2 & 24.7 & 0.56 \\
\hline Smilodon populator ${ }^{c}$ & 42.8 & 19.0 & 0.44 \\
\hline
\end{tabular}

${ }^{\mathrm{a}}$ Christiansen, 2007; ${ }^{\mathrm{b}}$ Werdelin and Lewis, 2001; ${ }^{\mathrm{c}}$ Palmqvist et al., 2007. 


\section{Table 4 (on next page)}

Comparative measurements ( $\mathrm{mm}$ ) of African fossil Chasmaporthetes and Lycyaenops maxillary premolars. 
Table 4. Comparative measurements ( $\mathrm{mm})$ of African fossil Chasmaporthetes and Lycyaenops maxillary premolars

\begin{tabular}{|c|c|c|c|c|c|c|c|}
\hline \multirow[b]{2}{*}{ Specimen $^{1}$} & \multirow[b]{2}{*}{ Deposit } & \multicolumn{2}{|c|}{$\mathrm{P} 2$} & \multicolumn{2}{|c|}{ P3 } & \multicolumn{2}{|c|}{ P4 } \\
\hline & & MD & $\mathrm{BL}$ & MD & $\mathrm{BL}$ & $\mathrm{MD}$ & $\mathrm{BL}$ \\
\hline \multicolumn{8}{|c|}{ Chasmaporthetes nitidula } \\
\hline SK 305 & Swartkrans Member 1 & $15.8 *$ & 10.7 & $20.3^{*}$ & 12.9 & 32.7 & 15.3 \\
\hline SK 306 & Swartkrans Member 1 & & & 19.6 & 13.6 & $32.4^{*}$ & 14.8 \\
\hline SK 307 & Swartkrans Member 1 & & & & & 32.4 & 14.5 \\
\hline SK 309 & Swartkrans Member 1 & & & 21.1 & 14.6 & & \\
\hline SK 310 & Swartkrans Member 1 & 18.8 & 11.9 & & & & \\
\hline SK 311 & Swartkrans Member 1 & 18.4 & 12.5 & & & & \\
\hline SK 312 & Swartkrans Member 1 & & & 21.9 & 14.0 & & $15.8^{*}$ \\
\hline SK 313 & Swartkrans Member 1 & & & 20.8 & 14.4 & & \\
\hline SK 379 & Swartkrans Member 1 & 19.5 & 12.0 & & & & \\
\hline SKX 29205 & Swartkrans Member 3 & & & 22.4 & $12.8^{*}$ & & \\
\hline SKX 22992/72 & Swartkrans Member 3 & & & & & $30.8 *$ & 15.8 \\
\hline SF 363 & Sterkfontein Member 4 & & & & & & 15.4 \\
\hline \multicolumn{8}{|l|}{ Lycyaenops silberbergi } \\
\hline DN 404 & Drimolen Main Quarry & & & $20.2 *$ & $11.6 *$ & 31.5 & 13.3 \\
\hline DN 974 & Drimolen Main Quarry & & & 20.4 & 13.5 & & \\
\hline STS 130 & Sterkfontein Member $2^{2}$ & & & 23.8 & $14.5^{*}$ & & \\
\hline STS 135 & Sterkfontein Member 4 & & & 19.6 & 11.9 & & \\
\hline SF $383 / 373$ & Sterkfontein Member 4 & & & 22.6 & & & \\
\hline SF $369 / 373$ & Sterkfontein Member 4 & & & 22.8 & & & \\
\hline SF 408 & Sterkfontein Member 4 & & & 20.3 & & & \\
\hline SF 463 & Sterkfontein Member 4 & 17.1 & 11.0 & & & & \\
\hline \multicolumn{8}{|c|}{ Lycyaenops cf. L. silberbergi } \\
\hline NHM AS 7.VI.35 & Laetoli (Laetolil Beds, Upper Unit) & & & 17.7 & 12.5 & & \\
\hline LAET 75-494 & Laetoli (Unknown level) & 19.1 & 11.0 & & & & \\
\hline
\end{tabular}

*Minimum value given damage to measured region.

${ }^{1}$ All measurements reported are by the authors except those for Sterkfontein (SF) premolars reported by Turner (1987) and Laetoli premolars reported by Werdelin and Dehghani, 2011).

${ }^{2}$ The stratigraphic origin of the STS 120 L. silberbergi type specimen from Sterkfontein is uncertain but may be derived from Member 2 or 3 (Brain, 1981). 


\section{Table 5 (on next page)}

Linear dimensions $(\mathrm{mm}$ ) of the Drimolen Main Quarry Antidorcas recki horn cores. 
Table 5. Linear dimensions ( $\mathrm{mm}$ ) of the Drimolen Main Quarry Antidorcas recki horn cores.

\begin{tabular}{lccc}
\hline & DN Specimen & Anteroposterior depth & Mediolateral width \\
\hline Male & & & \\
& 224 & 43.6 & 28.1 \\
& 890 & 40.5 & 28.0 \\
Female & 1060 & 42.2 & 28.9 \\
& 3294 & 35.7 & \\
& 995 & & \\
& $2483 \mathrm{a}$ & 17.5 & 14.6 \\
& 4438 & 18.2 & 16.1 \\
\hline
\end{tabular}




\section{Table 6(on next page)}

Comparative measurements ( $\mathrm{mm}$ ) of the DNH 2850 Metridiochoerus sp. right immature third metatarsal and fossil and extant adult suid third metatarsals. 
Table 6. Comparative measurements ( $\mathrm{mm}$ ) of the DN 2850 Suidae gen. et sp. indet. right immature third metatarsal and fossil and extant adult suid third metatarsals.

\begin{tabular}{|c|c|c|c|c|c|c|c|c|c|c|}
\hline \multirow[b]{2}{*}{ Measurement } & \multirow[b]{2}{*}{ DN 2850} & \multirow[b]{2}{*}{ G 8105} & \multicolumn{4}{|c|}{ Phacochoerus aethiopicus } & \multicolumn{4}{|c|}{ Potamochoerus porcus } \\
\hline & & & Mean & Min. & Max. & $n$ & Mean & Min. & Max. & $n$ \\
\hline Proximal dorsoventral depth & 22.0 & 30.0 & 19.6 & 18.1 & 20.9 & 6 & 22.1 & 21.3 & 23.3 & 4 \\
\hline Distal mediolateral width & 16.2 & - & 15.4 & 13.7 & 16.9 & 5 & 15.7 & 14.3 & 16.9 & 4 \\
\hline Distal dorsoventral depth & $\mathbf{1 7 . 0}$ & - & 15.5 & 14.6 & 16.5 & 6 & 16.5 & 15.7 & 17.7 & 4 \\
\hline
\end{tabular}


Table 7 (on next page)

McIntosh evenness statistic values for the Drimolen Main Quarry and comparative South African fossil assemblages. 
Table 7. McIntosh evenness statistic values for the Drimolen Main Quarry and comparative South African fossil assemblages.

\begin{tabular}{cc}
\hline Site* & Evenness \\
\cline { 2 - 2 } Grimolen Main Quarry & 0.71 \\
Gladysvale & 0.60 \\
Haasgat HGD & 0.92 \\
Kromdraai A & 0.72 \\
Kromdraai B & 0.83 \\
Makapansgat 2 & 0.76 \\
Makapansgat 3 & 0.93 \\
Makapansgat 4 & 0.81 \\
Makapansgat 5 & 0.84 \\
Sterkfontein Member 4 & 0.78 \\
Sterkfontein 53 Breccia & 0.67 \\
Sterkfontein Olduwan Infill & 0.86 \\
Sterkfontein Member 5 West & 0.74 \\
Swartkrans Member 1 Lower Bank & 0.84 \\
Swartkrans Member 2 & 0.83 \\
Swartkrans Member 3 & 0.86 \\
\hline
\end{tabular}

*Data from sources listed in Adams $(2006,2010)$ but modified to exclude hominin taxa from the calculation. 
1

Aerial photograph and map of the Drimolen Palaeocave System relative to other penecontemporaneous South African fossil sites.

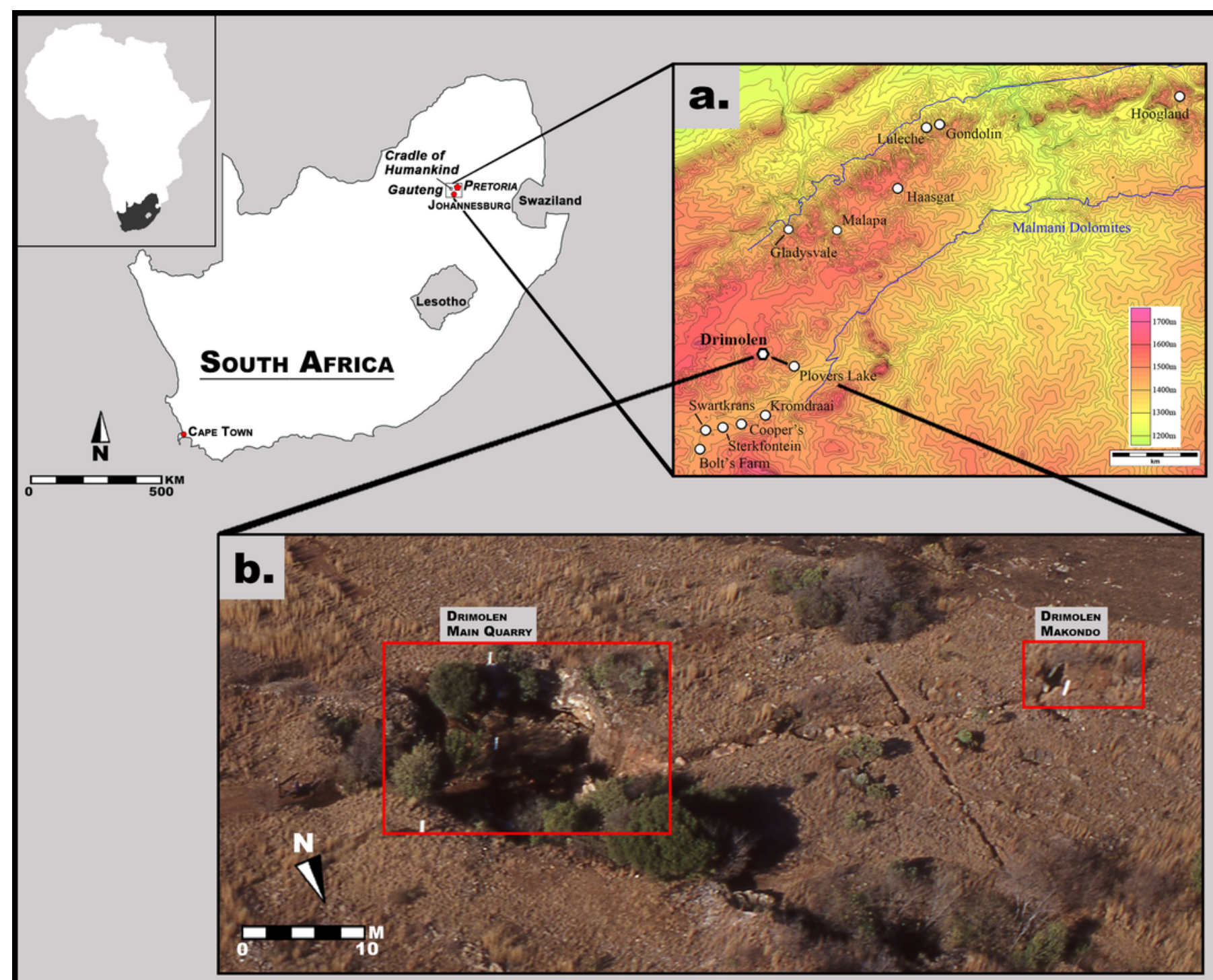


2

Schematic plan of the Drimolen Main Quarry excavation area and deposits.

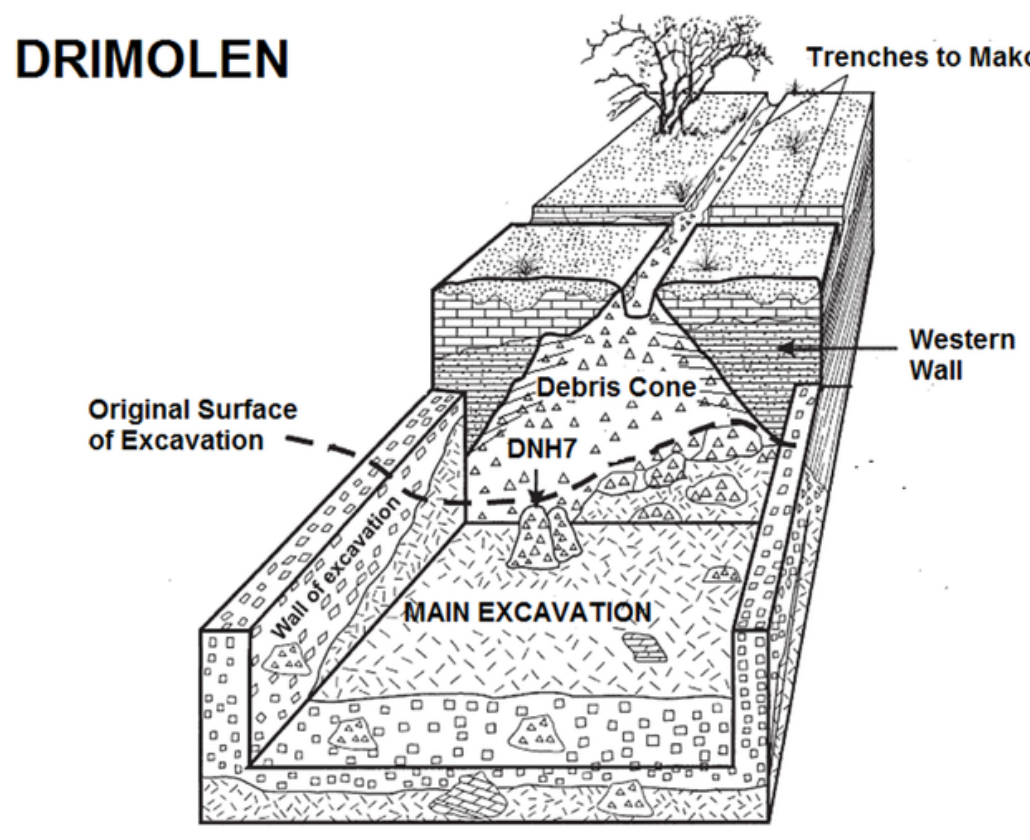

MAIN QUARRY
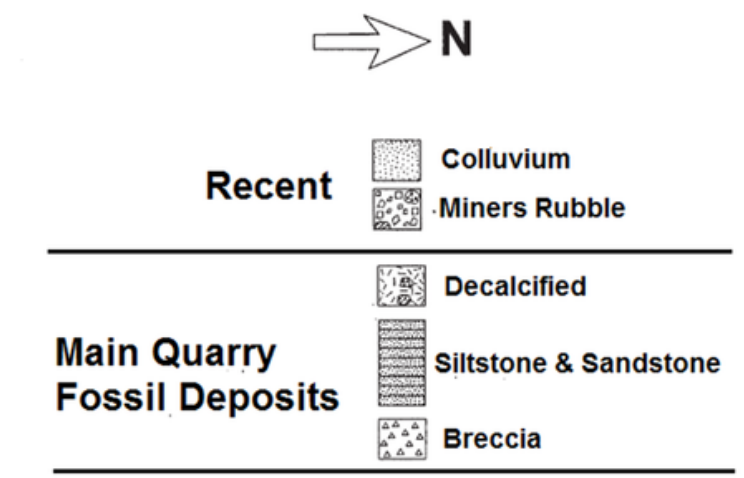

Malmani Dolomite

(after Keyser et al., 2000) not to scale 


\section{3}

Order Carnivora specimens attributed to the Family Felidae from the Drimolen Main Quarry.

A, DN 2791 Dinofelis cf. barlowi right maxillary canine, buccal (left) and distal (right) views.

B, DN 976 Megantereon whitei left P4, buccal (left) and lingual (right) views. C, DN 3254 Megantereon whitei left mandibular corpus, lateral (left) and anterior oblique (right) view of surface scan to highlight sharp diastema margin and mandibular flange. Scale bars equal 1 $\mathrm{cm}$.

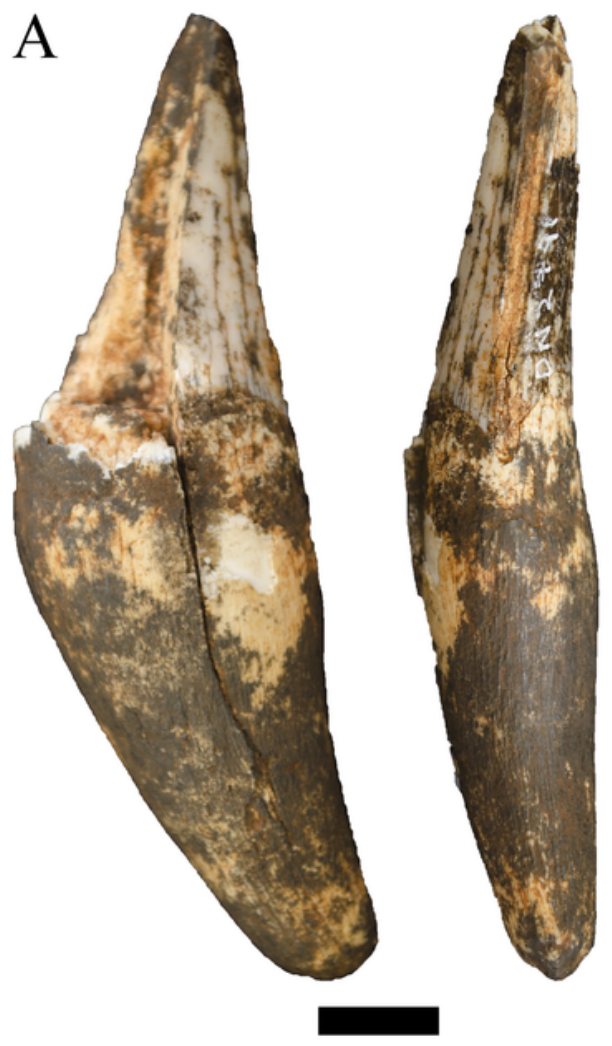

B

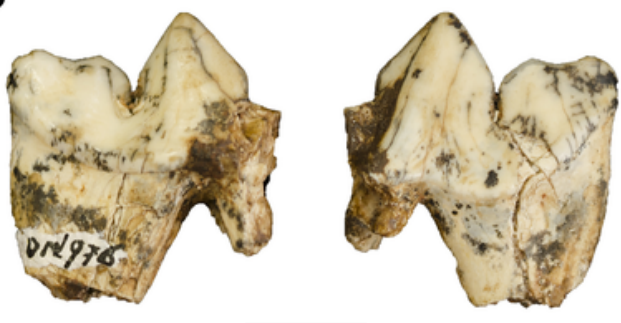

C
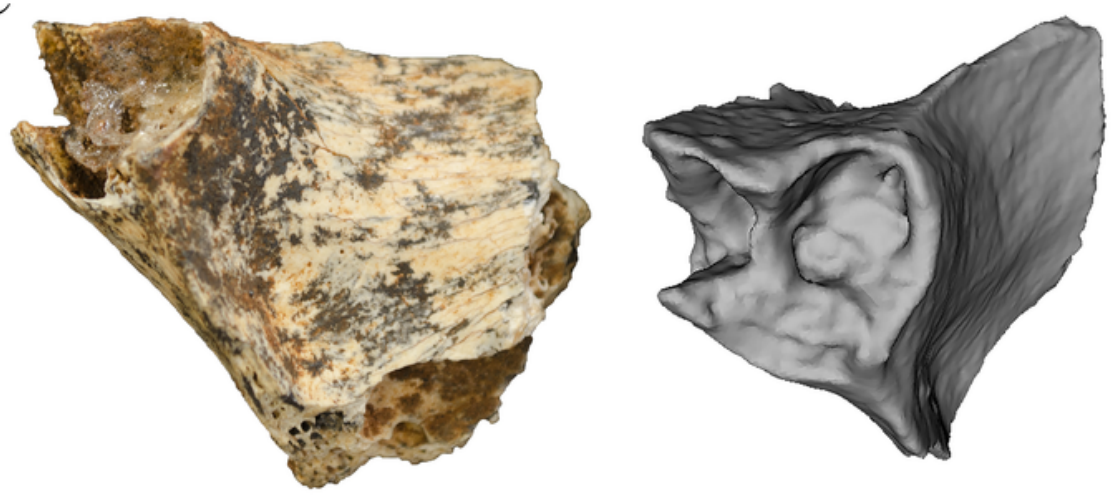
4

Bivariate plot of select Felidae maxillary canine MD length on BL width ( $\mathrm{mm}$ ), including DN 2791 Dinofelis cf. barlowi. Metrics and regression equations presented in Table 3.

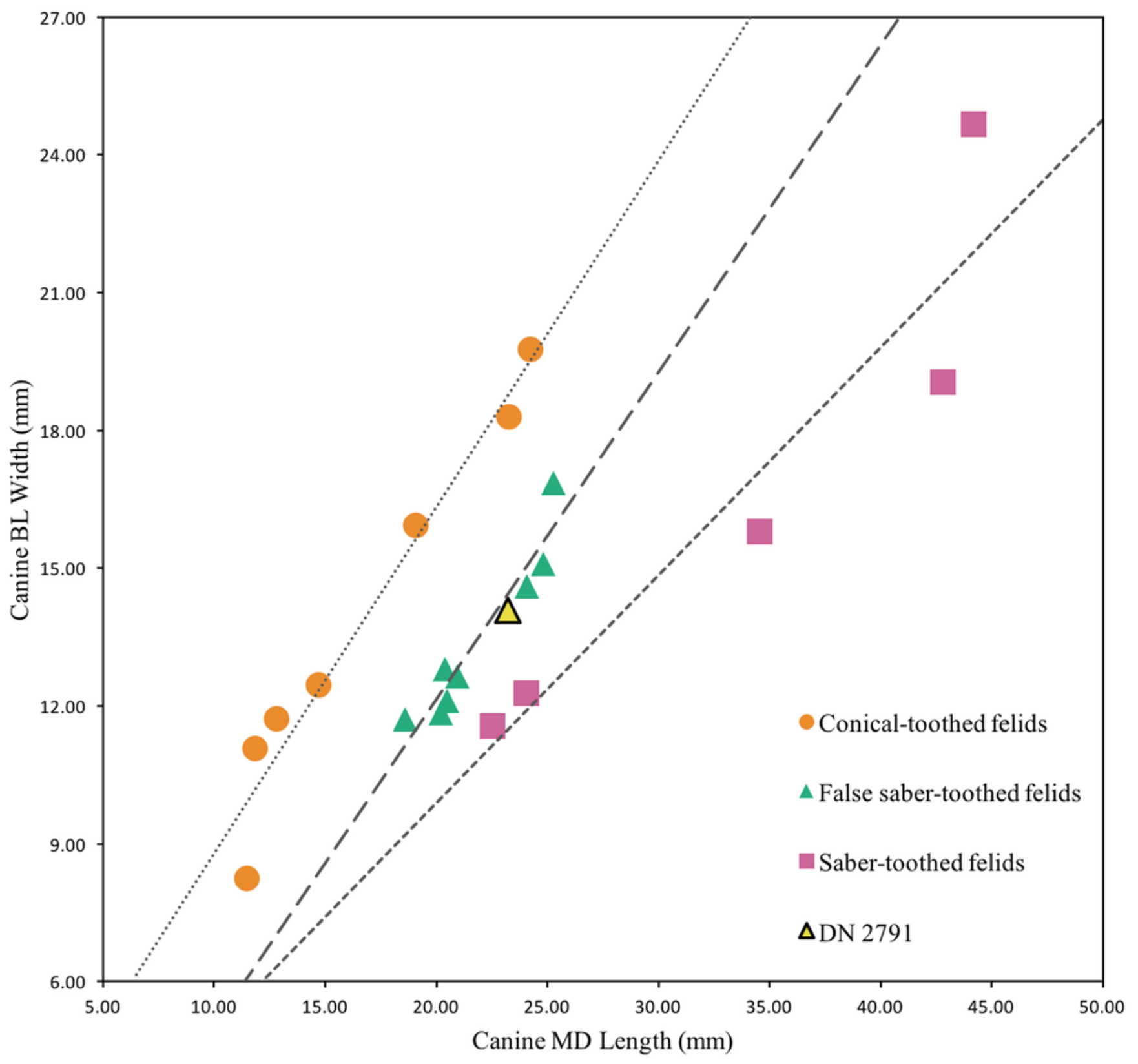




\section{5}

Order Carnivora specimens attributed to the Family Felidae and Hyaenidae from the Drimolen Main Quarry.

A, DN 4300 Felidae gen. et sp. indet. right P4, buccal view. B, DN 974 Lycyaenops silberbergi right P3, occlusal (top), lingual (left) and buccal (right) views. Scale bars equal $1 \mathrm{~cm}$.

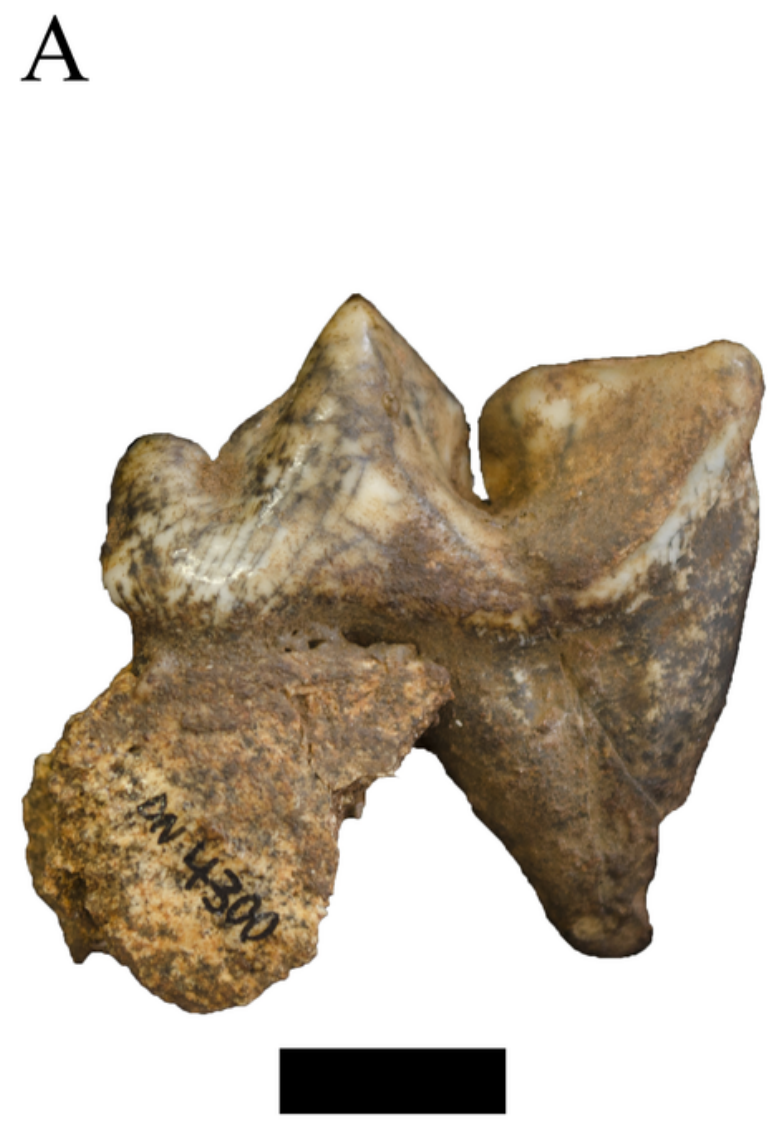

B

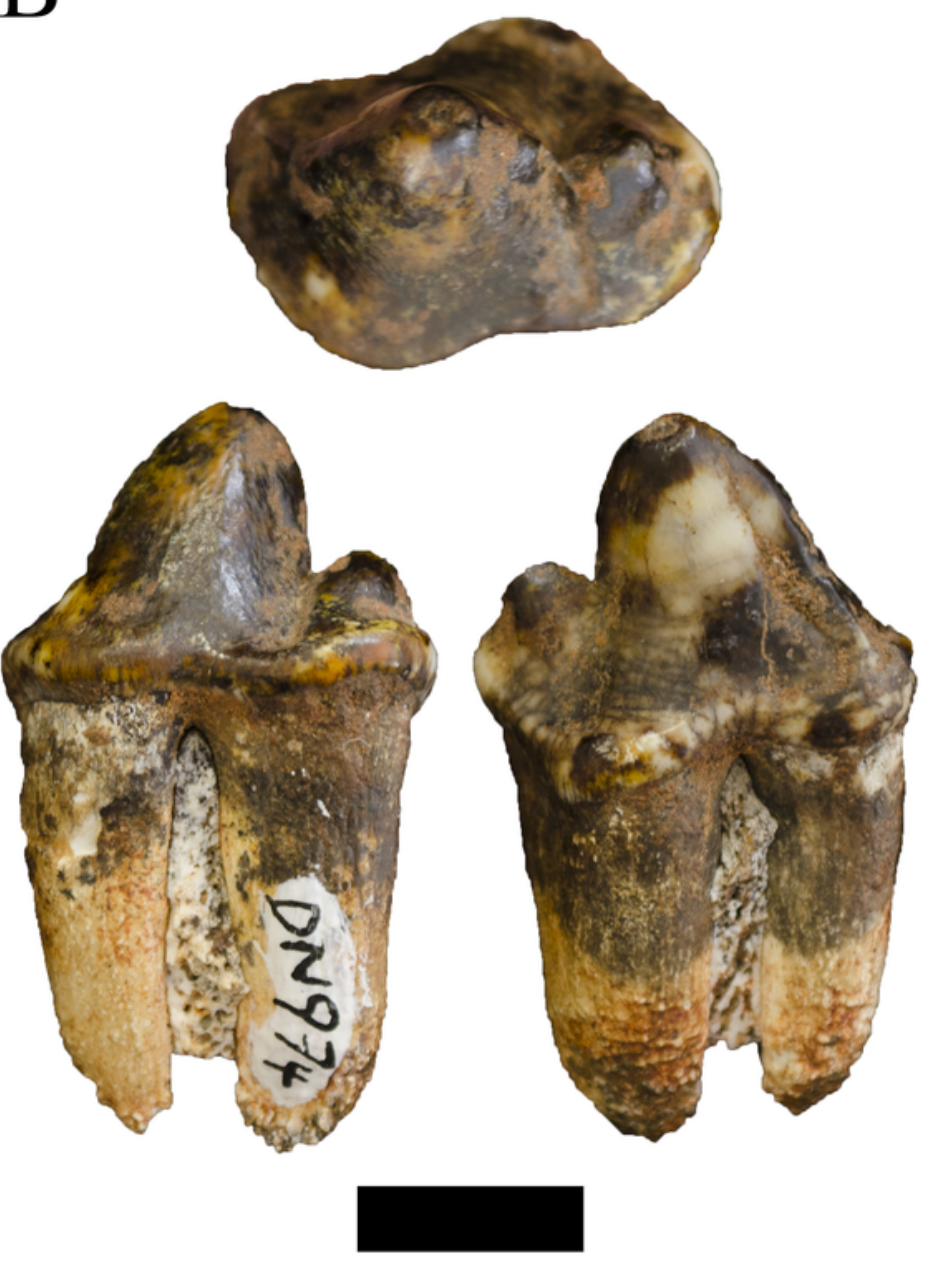




\section{6}

Order Cetartiodactyla specimens attributed to the Family Bovidae from the Drimolen Main Quarry.

A, DN 2790, Damaliscus sp. right horn core, medial view. B, DN 748a and 748b, Megalotragus sp. right M2 and M3, occlusal view. C, DN 1015, Alcelaphini gen. et sp. indet. left mandible, occlusal view. D, DN 1013 Alcelaphini gen. et sp. indet. right horn core, anterior (probable) view. Scale bars equal $1 \mathrm{~cm}$.

A

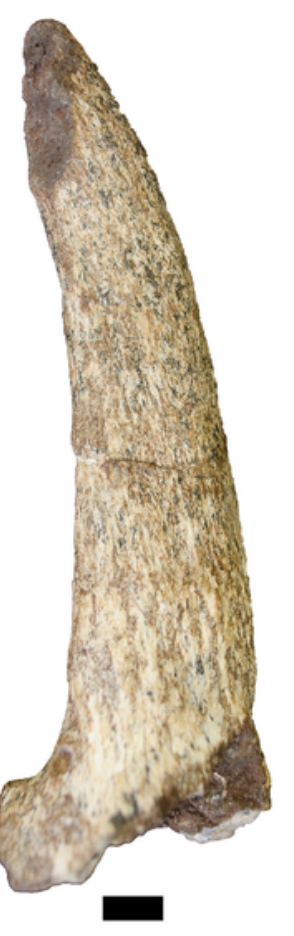

$\mathrm{D}$

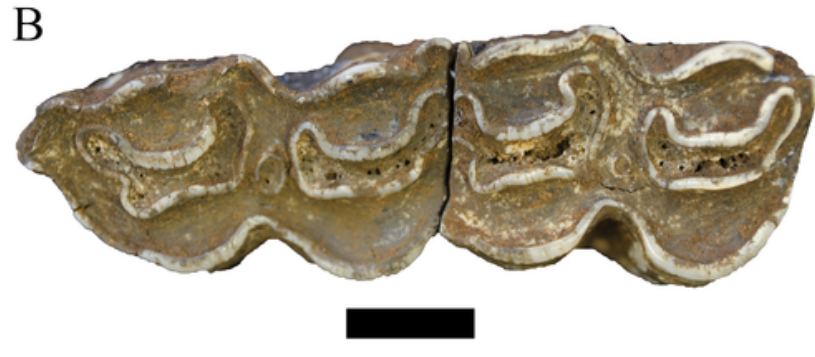

$\mathrm{C}$

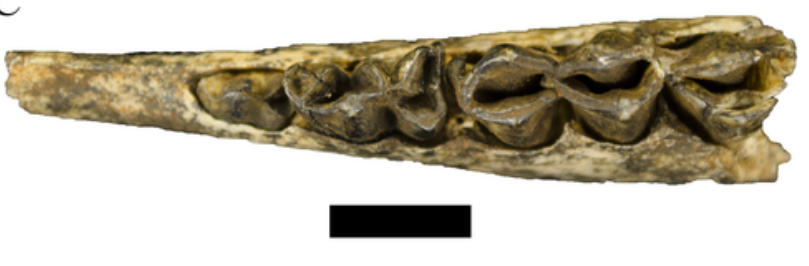

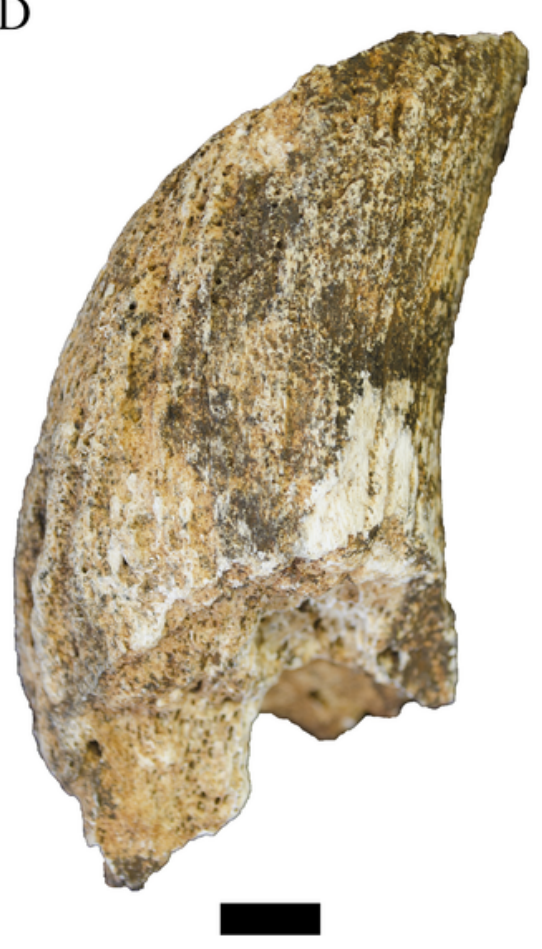




\section{7}

Order Cetartiodactyla specimens attributed to the Family Bovidae from the Drimolen Main Quarry.

A, DN 1060, Antidorcas recki right male horn core, medial view (left); DN 995, Antidorcas recki left female horn core, medial view (right). B, DN 438, Oreotragus sp. right mandible, occlusal view. C, DN 120, Tragelaphus sp. right mandible, occlusal view. Scale bars equal 1 $\mathrm{cm}$.

A

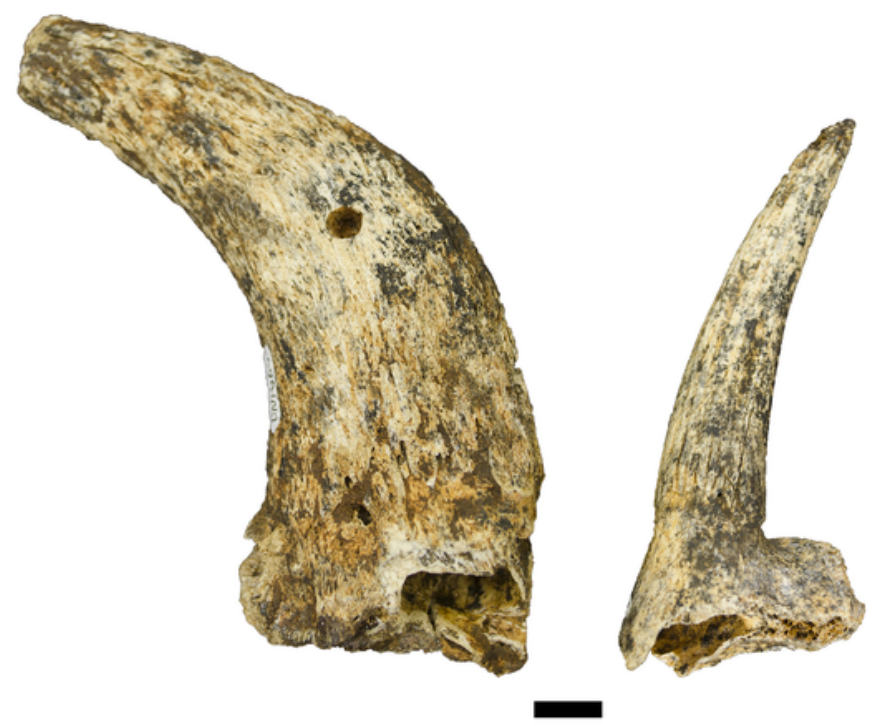

B

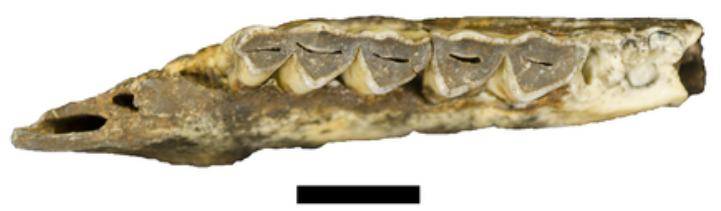

$\mathrm{C}$

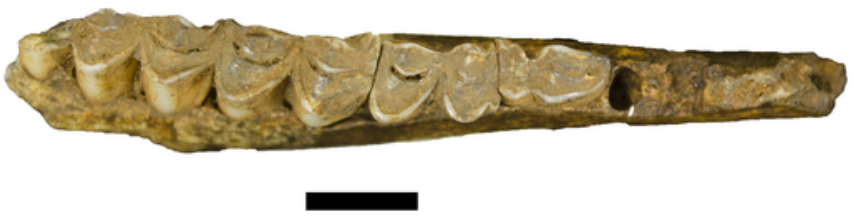


8

Order Cetartiodactyla specimens attributed to the Families Giraffidae and Suidae from the Drimolen Main Quarry.

A, DN 1097, Giraffidae gen. et sp. indet. right humerus, anterior (left) and posterior (right) views. B, DN 2850, Suidae gen. et sp. indet. right third metatarsal, medial (left) and lateral (right) views. Scale bars equal $1 \mathrm{~cm}$.

A

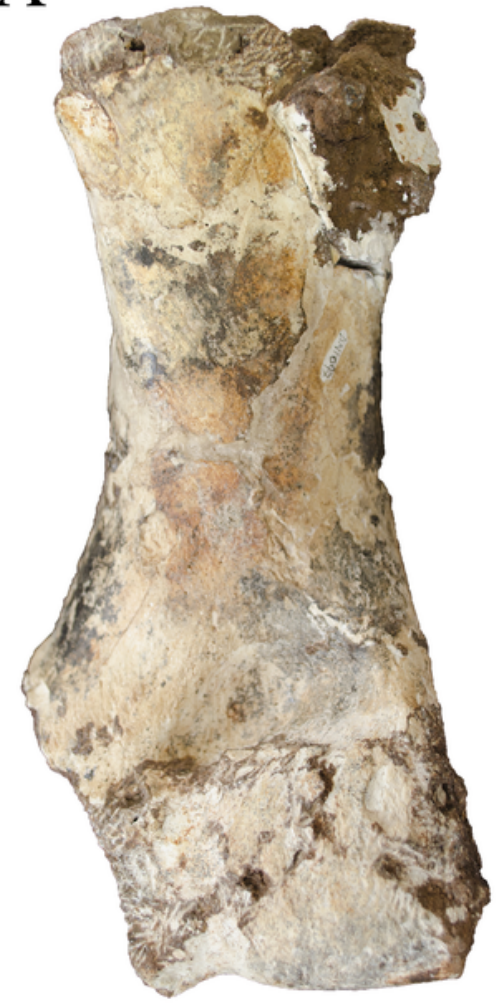

B

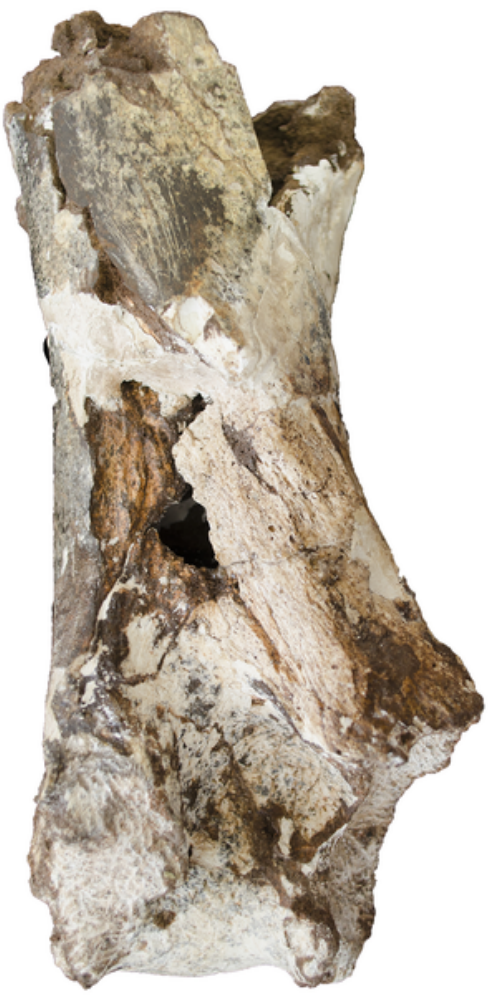

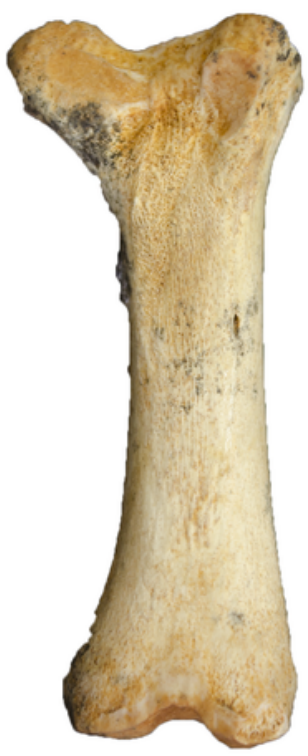


9

Specimens attributed to the Orders Proboscidea, Rodentia, and Tubulidentata from the Drimolen Main Quarry.

A, DN 4335, Elephantidae gen. et sp. indet., maxillary tusk fragment, internal view. B, DN 2760 Hystrix sp. left maxillary molar, occlusal view. C, DN 1062 Orycteropus cf. afer right proximal radius, posteromedial view. Scale bars equal $1 \mathrm{~cm}$. 


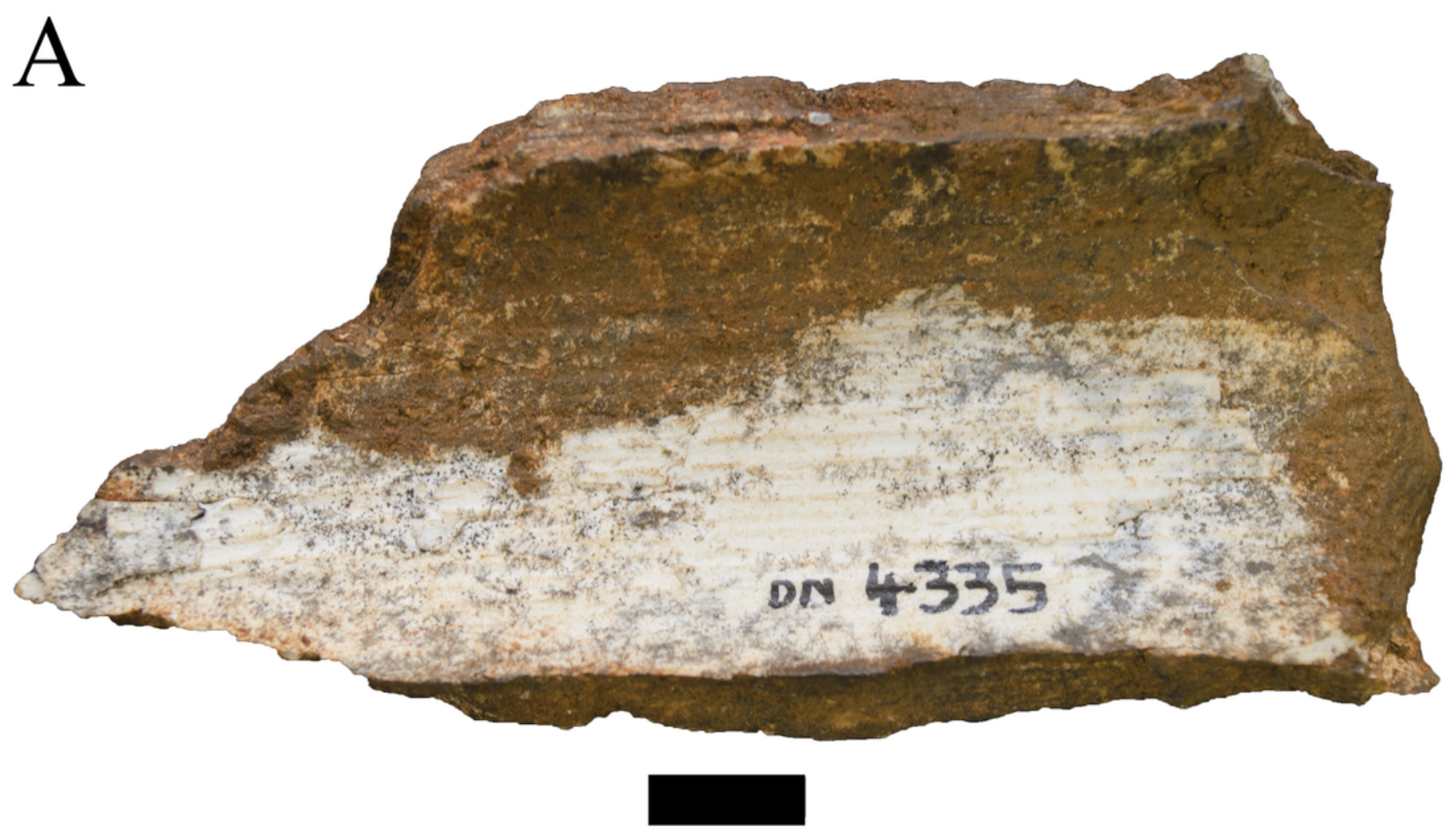

B
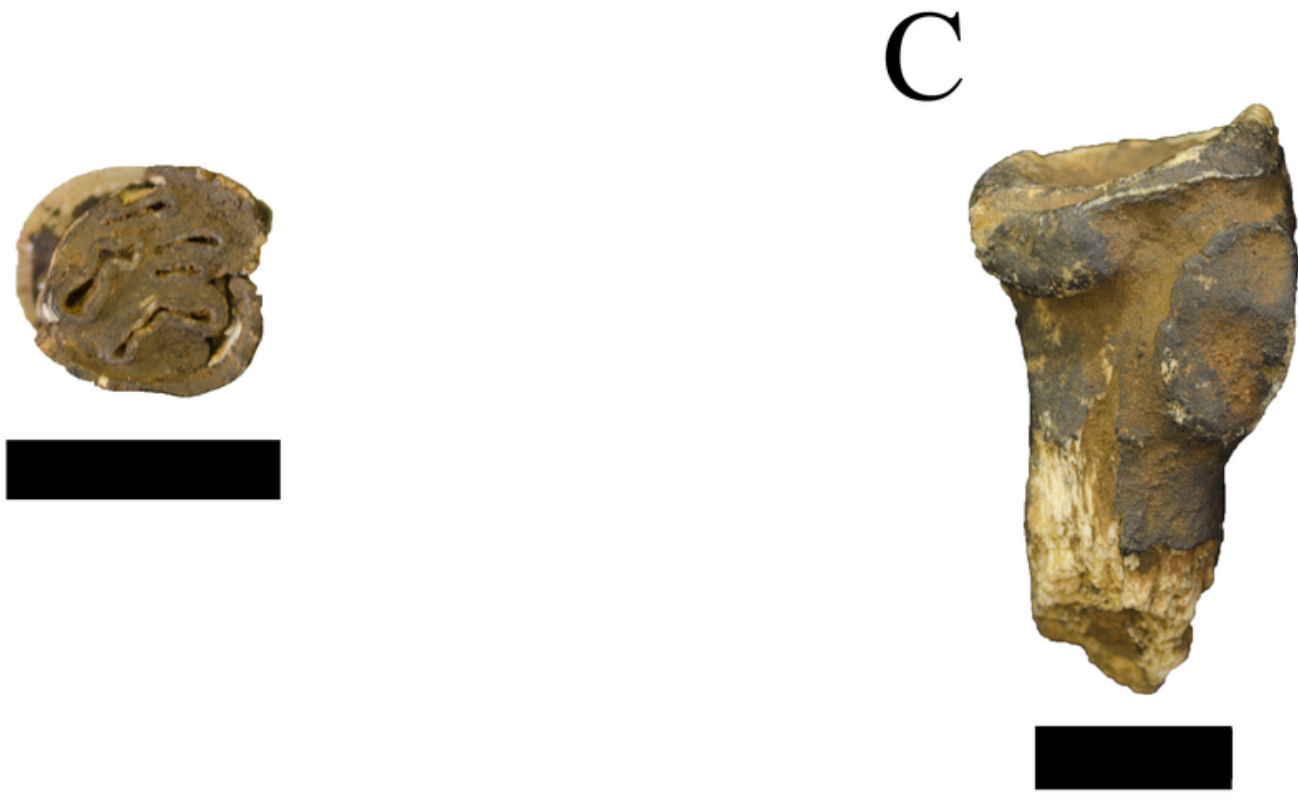